\title{
Electronic structures of silver oxides
}

\author{
Jeremy P. Allen, ${ }^{*}$ David O. Scanlon, and Graeme W. Watson ${ }^{\dagger}$ \\ School of Chemistry and CRANN, Trinity College Dublin, Dublin 2, Ireland \\ (Received 11 May 2011; revised manuscript received 4 August 2011; published 26 September 2011)
}

\begin{abstract}
The oxides of silver have a number of important technological applications, including use in battery technology, catalysis, and in the treatment of dermatological conditions. However, only the $\operatorname{Ag}_{2} \mathrm{O}$ phase has been well characterized in previous work. To this end, this paper characterizes the electronic structures of the major oxide forms, namely, $\mathrm{Ag}_{2} \mathrm{O}, \mathrm{Ag}_{2} \mathrm{O}_{3}$, and $\mathrm{AgO}$, using standard density functional theory (DFT), Hartree-Fock, and hybrid-DFT approaches. The optical properties are also assessed for these materials, enabling comparisons to be drawn to experiment and the origin of optical band gaps to be explained. The calculated optical gaps also suggest that electrodeposited $\mathrm{Ag}_{2} \mathrm{O}$ films may not consist of pure material. Hartree-Fock calculations are seen to fail to model $\mathrm{Ag}(\mathrm{I})$ species correctly, due to the neglect of correlation. DFT and hybrid-DFT methods are seen to perform better, but problems due to the lack of van der Waals interactions are identified. Preliminary calculations using empirical dispersion corrections are discussed.
\end{abstract}

DOI: 10.1103/PhysRevB.84.115141

PACS number(s): 71.20.-b, 71.20.Nr, 71.15.Mb

\section{INTRODUCTION}

The oxides of silver are known to exhibit both $\mathrm{Ag}(\mathrm{I})$ and $\operatorname{Ag}(\mathrm{III})$ oxidation states, giving rise to a number of different phases. The range of different oxide stoichiometries differentiates it from the related copper-oxygen and goldoxygen systems, which are much more restricted. Binary oxides of copper exist in the form of $\mathrm{Cu}_{2} \mathrm{O}, \mathrm{CuO},{ }^{1}$ and the mixed valence $\mathrm{Cu}_{4} \mathrm{O}_{3} .{ }^{2}$ For gold, however, only the $\mathrm{Au}$ (III) oxide is known, $\mathrm{Au}_{2} \mathrm{O}_{3},{ }^{3}$ although $\mathrm{Au}_{2} \mathrm{O}$ has been suggested as a possible intermediate in its thermal decomposition. ${ }^{4}$ In the silver-oxygen system, monovalent $\mathrm{Ag}(\mathrm{I})\left(\mathrm{Ag}_{2} \mathrm{O}\right)$ (Ref. 5) and trivalent $\mathrm{Ag}$ (III) $\left(\mathrm{Ag}_{2} \mathrm{O}_{3}\right)$ (Refs. 6-8) binary oxides are known but there is no divalent $\mathrm{Ag}$ (II) oxide. Mixed valence oxides have also been reported, namely, $\mathrm{Ag}(\mathrm{I}, \mathrm{III}), \mathrm{AgO},{ }^{9}$ and the metallic $\mathrm{Ag}(\mathrm{II}, \mathrm{III}), \mathrm{Ag}_{3} \mathrm{O}_{4} \cdot{ }^{10-13}$ In addition, evidence also exists for $\mathrm{Ag}_{4} \mathrm{O}_{3}$, through the electrochemical reduction of $\mathrm{AgO},{ }^{14}$ and $\mathrm{Ag}_{6} \mathrm{O}_{2}$, which possesses $\left(\mathrm{Ag}_{6}\right)^{4+}$ clusters. ${ }^{15}$

The oxides of silver have a number of important applications. Both $\mathrm{Ag}_{2} \mathrm{O}$ and $\mathrm{AgO}$ have uses in battery technologies ${ }^{16-19}$ and antibacterial applications. ${ }^{20-22} \mathrm{Ag}_{2} \mathrm{O}$ is also used in molecular sensor technologies, ${ }^{23}$ for example, as an enzymeless glucose sensor with $\mathrm{Cu}^{23,24}$ water splitting, ${ }^{25}$ optical memories, ${ }^{26}$ and organic catalysis, for example, in transmetalation ${ }^{27}$ and the oxidation of aldehydes by molecular oxygen. ${ }^{28}$ Additionally, $\mathrm{Ag}_{2} \mathrm{O}$ is used as a component of a range of fast-ion conducting glasses of the form AgI$\mathrm{Ag}_{2} \mathrm{O}-\mathrm{MoO}_{3},{ }^{29} \mathrm{AgI}-\mathrm{Ag}_{2} \mathrm{O}-\mathrm{WO}_{3},{ }^{30} \mathrm{AgI}-\mathrm{Ag}_{2} \mathrm{O}-\mathrm{V}_{2} \mathrm{O}_{5},{ }^{31}$ and $\mathrm{AgI}-\mathrm{Ag}_{2} \mathrm{O}-\mathrm{P}_{2} \mathrm{O}_{5} \cdot{ }^{32}$

$\mathrm{Ag}_{2} \mathrm{O}$ has been the most widely studied of the different silver oxides, with investigations mainly focusing on the electronic structure of the material ${ }^{33-36}$ and the interaction and bonding between the silver and oxygen atoms (primarily concerning the degree of covalency). ${ }^{33,37,38}$ The closed shell $d^{10}$ nature of $\operatorname{Ag}(\mathrm{I})$ may be thought to give rise to a purely ionic system, however, calculations by Czyżyk et al. ${ }^{34}$ and Deb and Chatterjee ${ }^{33}$ have shown that the valence band of $\mathrm{Ag}_{2} \mathrm{O}$ consists mainly of $\mathrm{O} 2 p$ and $\mathrm{Ag} 4 d$ states with a significant, albeit small, contribution from $\mathrm{Ag} 5 s$ states. $\mathrm{X}$-ray photoelectron spectroscopy (XPS), and Auger-electron and bremsstrahlung isochromat spectroscopy (BIS) studies by Tjeng et al. ${ }^{35}$ report a fundamental band gap of $1.3 \mathrm{eV}$. Calculated band gaps using standard density functional theory (DFT) methods are typically underestimated, with reported values of 0.40 (Ref. 34) and $0.08 \mathrm{eV},{ }^{39}$ or the material is predicted to be metallic. ${ }^{33}$ The experimental optical band gap, obtained from absorption spectra of $\mathrm{Ag}_{2} \mathrm{O}$ thin films, is reported to be $2.25 \mathrm{eV} .{ }^{40}$ More recent experimental studies on nanoparticles ${ }^{41}$ and electrodeposited thin films, ${ }^{42}$ however, have placed the optical band gap at $1.46 \mathrm{eV}$.

$\mathrm{Ag}_{2} \mathrm{O}_{3}$ has had considerably less attention in the literature than $\mathrm{Ag}_{2} \mathrm{O}$, most likely due to its poor stability. Studies of $\mathrm{Ag}_{2} \mathrm{O}_{3}$ have either detailed the crystal structure ${ }^{6-8}$ or used x-ray absorption near-edge spectroscopy (XANES) and ${ }^{109} \mathrm{Ag}$ magic angle spinning (MAS) NMR to characterize $\mathrm{Ag}$ (III) ions. In XANES, $\operatorname{Ag}(\mathrm{III})$ shows a higher-energy $L_{1}$ peak and a more intense $L_{3}$ peak than $\operatorname{Ag}(\mathrm{I})$ species due to a lower occupation of the $d$ shell. ${ }^{43}$ The ${ }^{109}$ Ag MAS NMR study of van Wüllen et al. showed that $\mathrm{Ag}(\mathrm{III})$ ions have a higher chemical shift in NMR spectra than $\mathrm{Ag}(\mathrm{I})$ ions ${ }^{44}$ Using DFT, Burdett and Sevov ${ }^{45}$ previously calculated a density of states for $\mathrm{Ag}_{2} \mathrm{O}_{3}$, along with other group 11 sesquioxides, finding a band gap of $0.96 \mathrm{eV}$ and mixing of the $\mathrm{O} 2 p$ and $\mathrm{Ag} 4 d$ states in the valence band.

Although $\mathrm{AgO}$ has also been studied to a lesser extent than $\operatorname{Ag}_{2} \mathrm{O}$, a number of investigations have attempted to elucidate the exact oxidation states present. XANES ${ }^{43}{ }^{109} \mathrm{Ag}$ MAS NMR, ${ }^{44}$ and $x$-ray absorption spectroscopy ${ }^{46}$ studies have identified the material as containing both $\operatorname{Ag}(\mathrm{I})$ and $\mathrm{Ag}$ (III) valences. XPS data, ${ }^{36,46,47}$ however, has led to some controversy through the observation of two peaks for $\mathrm{O} 1 \mathrm{~s}$, suggesting two oxidation states for O. Bielmann et al. ${ }^{47}$ attributed this to $\mathrm{AgO}$ possessing a mixed (I,II) oxidation state with hole states present on the $\mathrm{O}$ anions, based on early theoretical studies by Park et al..$^{48}$ However, the second peak was explained by Hoflund et al. ${ }^{36}$ to be a result of $\mathrm{Ag}_{2} \mathrm{CO}_{3}$ impurities, which are present due to it having a greater thermal stability than $\mathrm{AgO}$ and therefore it is very difficult to remove. Furthermore, we previously used a hybrid-DFT methodology to show that $\mathrm{AgO}$ exists with $\operatorname{Ag}(\mathrm{I})$ and $\operatorname{Ag}(\mathrm{III})$ oxidation states, and that standard DFT methods are unable to capture 
this mixed valence nature, predicting a symmetric $\mathrm{Ag}(\mathrm{II}) \mathrm{O}$ structure. ${ }^{49}$

This paper examines the electronic structure and bonding properties of $\mathrm{Ag}_{2} \mathrm{O}, \mathrm{Ag}_{2} \mathrm{O}_{3}$, and $\mathrm{AgO}$ through the characterization of the densities of states and band structures using standard DFT, Hartree-Fock, and hybrid-DFT methodologies. This will provide a comprehensive and comparative analysis of these common silver oxides, allowing a full understanding of the structure and bonding in the silver-oxygen system.

\section{COMPUTATIONAL METHODS}

All calculations in this paper are performed using the periodic DFT code VASP. ${ }^{50,51}$ This uses a plane-wave basis set to describe the valence electronic states, with interactions between the cores $(\mathrm{Ag}:[\mathrm{Kr}]$ and $\mathrm{O}:[\mathrm{He}])$ and the valence electrons described using the projector-augmented wave $^{52,53}$ (PAW) method. This paper uses three functionals for simulating the silver oxide structures. The first is the generalized gradient approximation (GGA) of Perdew, Burke, and Ernzerhof ${ }^{54}$ (PBE) functional. The second uses the hybridDFT approach of Heyd, Scuseria, and Ernzerhof (HSE06). ${ }^{55,56}$ The HSE06 method is a screened hybrid-DFT approach, in which a percentage of the PBE exchange is replaced with exact nonlocal Fock exchange. The HSE06 methodology, as described in more detail elsewhere, ${ }^{55-57}$ uses a screening of $\omega=0.11 \mathrm{bohr}^{-1}$ to partition the exchange into long- and short-range parts, where $25 \%$ of the PBE exchange in the short-range component is replaced with exact Fock exchange. Hybrid methods are more computationally demanding than the PBE functional; however, they are often found to give improved data for semiconductor systems, including atomic and electronic structure (including band gaps), ${ }^{58-61}$ optical transitions, ${ }^{62-64}$ and defective ${ }^{65-67}$ and magnetic ${ }^{68-70}$ systems. The third approach is the use of Hartree-Fock (HF), 100\% exchange and no correlation, to assess the role of correlation and full exchange. The accurate prediction of the band gap from a band structure is only possible using a quasiparticle approach, for example, the $G W$ method. However, HSE06 has been shown to afford reasonable values of direct and indirect fundamental gaps in comparison to experiment, and therefore the band gaps determined in this paper can be accepted with a reasonable level of confidence. ${ }^{59,71}$

The failure of DFT to model the mixed valence nature of $\mathrm{AgO}$ (Ref. 49) most likely results from the self-interaction error present in DFT, which favors the delocalization of highly correlated electrons. Although HSE06 is one approach to help correct this error, an alternative is the GGA $+U$ approach. This approach, which is less computationally demanding than HSE06, adds a correction, defined by the $+U$ term, to specific orbitals and acts as a penalty to the delocalization of electrons. The GGA $+U$ method has been previously shown to accurately describe polaronic $n$-type ${ }^{72-76}$ and $p$-type $\mathrm{e}^{77,78}$ systems. Furthermore, GGA $+U$ has also been of use to predict the correct mixed valence in reduced ceria, namely, $\mathrm{Ce}(\mathrm{III})$ and $\mathrm{Ce}(\mathrm{IV})$ ions, which GGA fails to accurately model. ${ }^{73,75}$ This method should therefore penalize against the formation of the equivalent $\mathrm{Ag}(\mathrm{II})$ ions, thus allowing the correct mixed valence of $\operatorname{Ag}(\mathrm{I}, \mathrm{III})$ to be reproduced. Both the value of the $U$ term and its ability to localize the $d$ electrons will be assessed through the application of the rotationally invariant form of DFT $+U .{ }^{79} \mathrm{As} \mathrm{Ag}_{2} \mathrm{O}$ and $\mathrm{Ag}_{2} \mathrm{O}_{3}$ do not have mixed oxidation states, this method is only used for modeling $\mathrm{AgO}$.

Equilibrium lattice parameters for the bulk systems were determined through a series of structural minimizations at different volumes. In each calculation, the atomic coordinates, lattice vectors, and angles were allowed to fully relax within the constraint of a fixed total cell volume. The resultant energy-volume curves were then fitted to the Murnaghan equation of state to obtain the equilibrium bulk cell volume..$^{80}$ This approach avoids potential problems of Pulay stress and changes in the basis set which can accompany volume changes in plane-wave calculations. A plane-wave cutoff of $400 \mathrm{eV}$ was used for all calculations and $k$-point grids of $4 \times 4 \times 4$, $4 \times 4 \times 6$, and $4 \times 6 \times 4$ were used for $\mathrm{Ag}_{2} \mathrm{O}, \mathrm{Ag}_{2} \mathrm{O}_{3}$, and $\mathrm{AgO}$, respectively, where $\mathrm{Ag}_{2} \mathrm{O}_{3}$ was modeled in its primitive unit cell. For each calculation, structural minimization was deemed complete when the forces on all atoms were less than $0.01 \mathrm{eV} \AA^{-1}$.

The optical absorption spectra, as well as the optical transition matrices, were calculated within the transversal approximation, ${ }^{81}$ as described by Scanlon et al. ${ }^{57}$ This approach sums all direct valence-band (VB) to conductionband (CB) transitions on $k$-point grids to determine the optical absorption and does not include indirect and intraband transitions. ${ }^{82}$ As only single-particle transitions are included, any electron-hole correlations would require higher-order electronic structure methods. ${ }^{83,84}$ However, this approach has been shown to provide reasonable optical absorption spectra in comparison to experiment. ${ }^{63,85-87}$

\section{RESULTS}

\section{A. Silver (I) oxide, $\mathbf{A g}_{2} \mathrm{O}$}

$\mathrm{Ag}_{2} \mathrm{O}$ is isostructural with $\mathrm{Cu}_{2} \mathrm{O}$ (Ref. 88) and crystallizes in the cubic $P n \overline{3} m$ space group, with a lattice vector of $4.73 \AA .{ }^{5}$ The unit cell [Fig. 1(a)] is highly symmetric and contains two interpenetrating cristobalite sublattices. The $\mathrm{Ag}(\mathrm{I})$ atoms are linearly coordinated to oxygen atoms, as expected for a $d^{10}$ species, ${ }^{89}$ whereas the oxygen atoms are tetrahedrally coordinated to the $\operatorname{Ag}(\mathrm{I})$ atoms, as detailed in Fig. 1(b). All bond distances within the system are equivalent, with $\mathrm{Ag}-\mathrm{O}$ and nearest-neighbor $\mathrm{Ag}-\mathrm{Ag}$ distances of 2.05 and $3.35 \AA$, respectively. Table I details the lattice vector and bond distances, with percentage differences to experiment, following structural minimization with the GGA, HSE06, and HF methods. The best reproduction of the experimental structure is seen with the hybrid-DFT functional, with a $2.0 \%$ difference to experiment, compared to $2.4 \%$ for GGA and $5.9 \%$ for HF. The HF approach is seen to give a significantly expanded lattice, relative to experiment, and the percentage errors seen for the GGA and HSE06 methods are also slightly larger than would normally be expected, ${ }^{57,63,90,91}$ which will be discussed in Sec. IV.

The band structure calculated with the GGA and HSE06 functionals along the space-group high-symmetry lines from Bradley and Cracknell ${ }^{92}$ are given in Fig. 2. Both methods give rise to a similar basic structure, which is also in broad agreement with previous calculations. ${ }^{33,34,38,39}$ However, the 


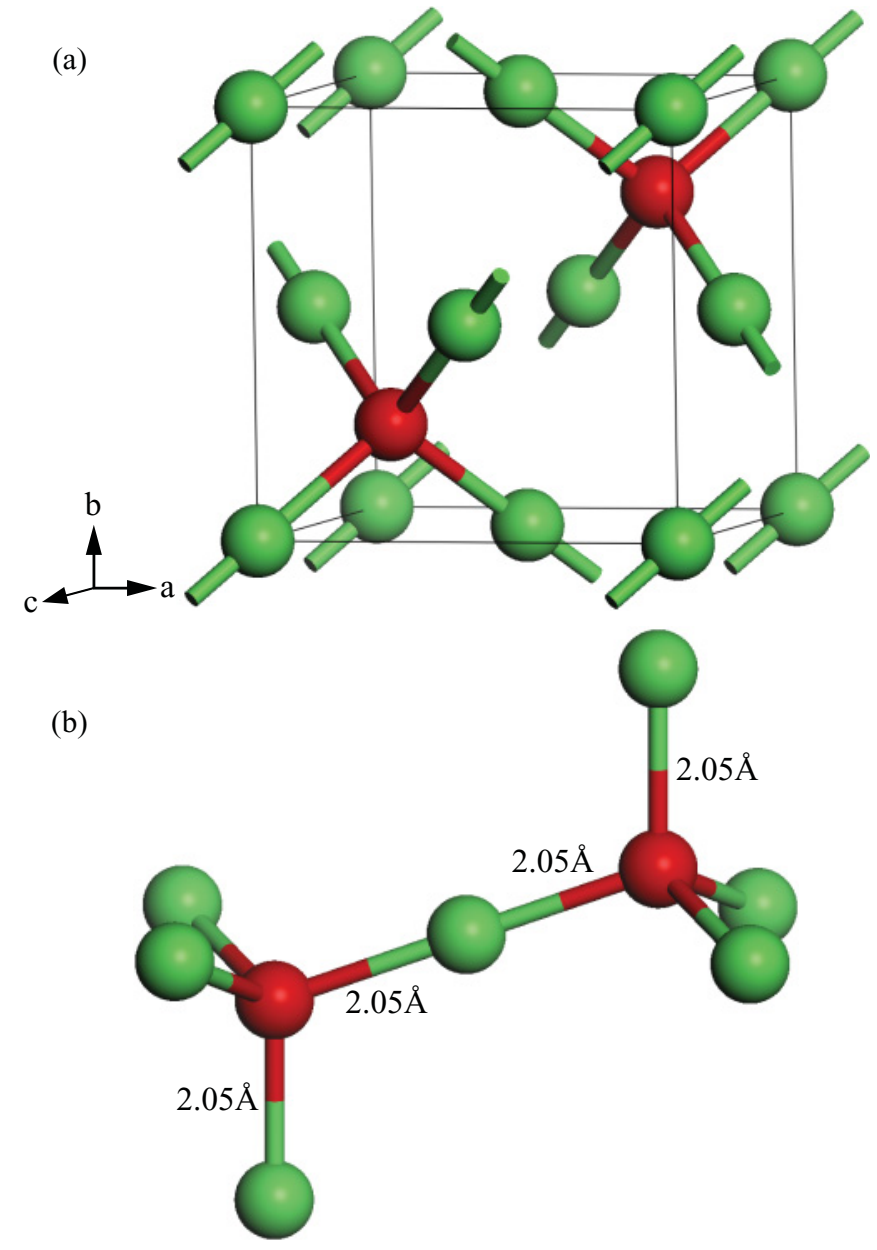

FIG. 1. (Color online) Atomic structure of (a) the unit cell of $\mathrm{Ag}_{2} \mathrm{O}$ and (b) the coordination environment of $\mathrm{Ag}(\mathrm{I})$ ions, with experimental bond lengths (Ref. 5). Silver (I) and oxygen atoms are colored green (light gray) and red (dark gray), respectively.

GGA functional fails to predict a band gap [Fig. 2(a)], giving rise to a metallic system through the overlap of the $\mathrm{VB}$ and $\mathrm{CB}$ at the $\Gamma$ point, similar to that seen by Deb and Chatterjee. ${ }^{33}$ This is greatly improved through the use of hybrid-DFT [Fig. 2(b)], where the CB is shifted up in energy, relative to the VB, opening up a band gap. In comparison to GGA, the HSE06 valence band is also slightly broadened, by $0.4 \mathrm{eV}$,

TABLE I. Experimental lattice vector and bond lengths for $\mathrm{Ag}_{2} \mathrm{O}$ with those calculated using GGA, HSE06, and HF methods. Percentage changes to experiment are given in parentheses and all values are in $\AA$, except for the cell volume, which has units of $\AA^{3}$.

\begin{tabular}{lcccc}
\hline \hline Property & GGA & HSE06 & HF & Experiment (Ref. 5) \\
\hline Lattice vector & 4.844 & 4.824 & 5.012 & 4.731 \\
& $(2.4)$ & $(2.0)$ & $(5.9)$ & \\
Volume & 113.64 & 112.27 & 125.90 & 105.86 \\
& $(7.1)$ & $(5.8)$ & $(18.9)$ & \\
Ag-O & 2.097 & 2.089 & 2.170 & 2.048 \\
& $(2.4)$ & $(2.0)$ & $(6.0)$ & \\
Ag-Ag & 3.425 & 3.411 & 3.544 & 3.345 \\
& $(2.4)$ & $(2.0)$ & $(5.9)$ & \\
\hline \hline
\end{tabular}
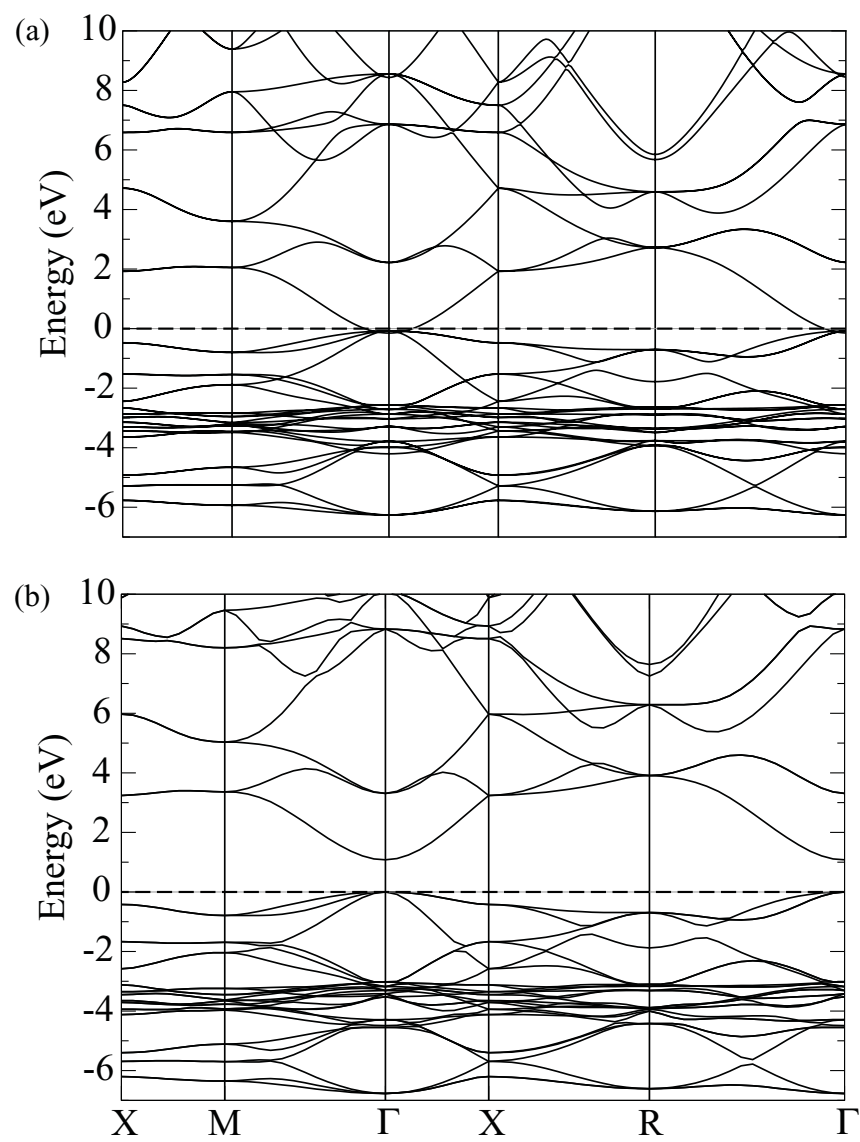

FIG. 2. Calculated band structure for $\mathrm{Ag}_{2} \mathrm{O}$ using the (a) GGA and (b) HSE06 functional. The top of the valence band in set to $0 \mathrm{eV}$, or, in the case of the GGA functional, the Fermi energy.

to a value of $6.8 \mathrm{eV}$, which is in better agreement with XPS data $(\sim 7 \mathrm{eV}) .{ }^{35}$ Both the valence-band maximum $(\mathrm{VBM})$ and conduction-band minimum (CBM) are located at the $\Gamma$ point, giving a direct fundamental band gap of $1.1 \mathrm{eV}$. This compares favorably with the XPS and BIS experimental fundamental band gap of $1.3 \mathrm{eV} .{ }^{35} \mathrm{HSE} 06$ was also seen to provide a band gap which was in very good agreement with experiment for isostructural $\mathrm{Cu}_{2} \mathrm{O} .{ }^{93}$ The HF-calculated band structure (not shown) is also qualitatively similar to those determined with GGA and HSE06. However, the direct fundamental band gap is considerably overestimated, with a value of $8.30 \mathrm{eV}$ at the $\Gamma$ point. This overestimation is unsurprising as HF methods are well known to predict unoccupied states which are too high in energy. ${ }^{94}$

The calculated total and partial (ion and $l$-quantum number decomposed) electronic densities of states (EDOS and PEDOS, respectively) using hybrid-DFT are shown for $\mathrm{Ag}_{2} \mathrm{O}$ in Fig. 3. The EDOS, dominated by the $\mathrm{Ag} 4 d$ and $\mathrm{O} 2 p$ states, can be broadly separated into five regions, with the valence band comprising regions I-IV and region $\mathrm{V}$ representing the conduction band. Region I is primarily made up of $\mathrm{O} 2 p$ states, with some mixing of $\mathrm{Ag} 4 d$ states. The lower limit of this region also includes a small amount of $\mathrm{Ag} 5 s$ states. Region II contains the majority of the Ag $4 d$ states with only a minor contribution from $\mathrm{O} 2 p$. Region III is similar to region I in that it comprises mixed $\mathrm{Ag} 4 d$ and O $2 p$ states. Region IV makes 


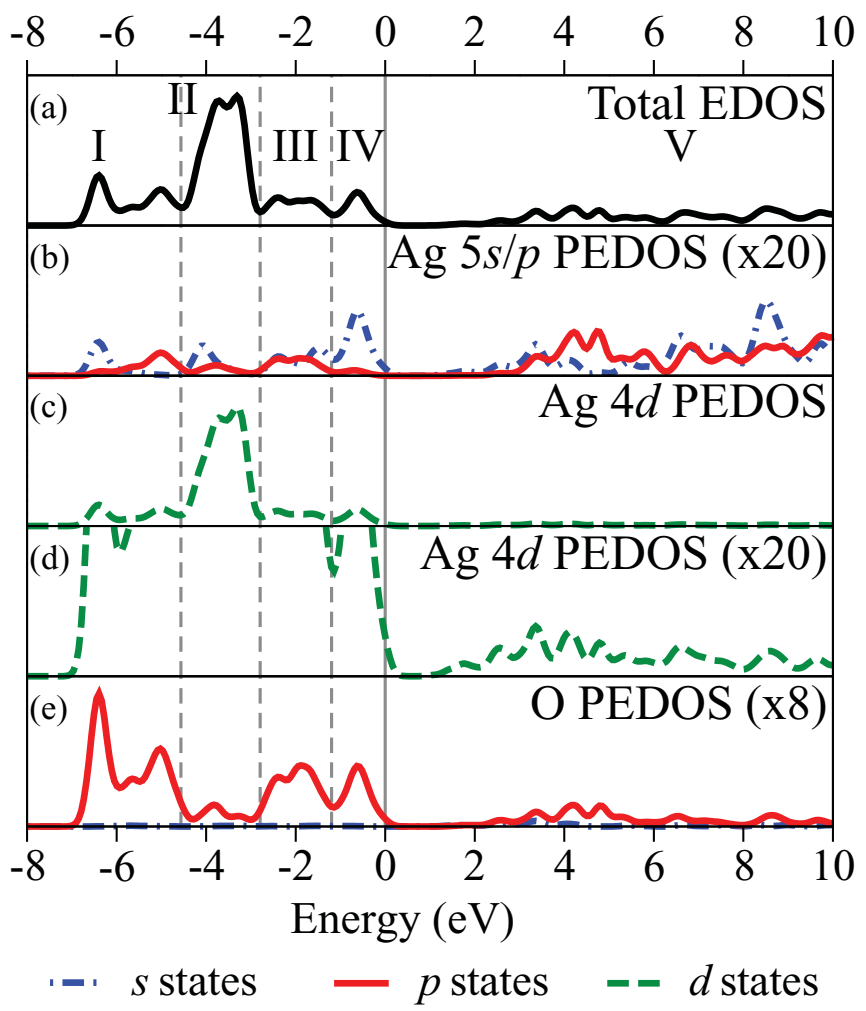

FIG. 3. (Color online) HSE06-calculated electronic density of states for $\mathrm{Ag}_{2} \mathrm{O}$. (a) Total EDOS, (b) Ag $5 s$ and $5 p$ PEDOS, (c) $\mathrm{Ag} 4 d$ PEDOS, (d) Ag $4 d$ PEDOS (multiplied to show the CB features), and (e) O PEDOS. The $s, p$, and $d$ states are colored blue (dashed-dotted), red (dashed), and green (solid), respectively. The Fermi energy is represented by the vertical solid gray line, which has been set to $0 \mathrm{eV}$.

up the VBM and is similar in character to the lower section of region $\mathrm{I}$. It is mainly a mix of $\mathrm{Ag} 4 d$ and $\mathrm{O} 2 p$ states, with a $\mathrm{Ag}$ $5 s$ contribution. The bottom of the conduction band, region $\mathrm{V}$, consists primarily of $\mathrm{Ag} 5 s, p$ and $4 d$ states, with the $d$ states having a stronger presence. The general appearance and features of the EDOS and PEDOS are consistent with previous studies. ${ }^{34,35,38,39,95}$ The HSE06 results are seen to be superior to those of GGA, again shown by the valence band width and the increased band gap. The density of states calculated using the GGA and HF methods are seen to be similar in appearance to the HSE06 method, albeit with reduced and enlarged band gaps, respectively, and are therefore not shown.

The observation of Ag $5 s$ states at the VBM and Ag $4 d$ states at the CBM are indicative of a partial deoccupation of $d$ states through $s$ - $d$ hybridization, rather than a $d^{10}$ Ag species. This partial deoccupation has also been reported in experimental Ag $L_{3}$ XANES spectra ${ }^{43}$ and computational studies. ${ }^{34,38,39,95}$ A similar bonding scheme with $s$ - $d$ hybridization has also been observed previously for $\mathrm{Cu}_{2} \mathrm{O} .^{96}$

\section{B. Silver (III) oxide, $\mathrm{Ag}_{2} \mathrm{O}_{3}$}

$\mathrm{Ag}_{2} \mathrm{O}_{3}$ possesses an orthorhombic structure (space group $\mathrm{Fdd2}$ ), ${ }^{7}$ shown in Fig. 4(a), and is isostructural with $\mathrm{Au}_{2} \mathrm{O}_{3} .{ }^{97}$ The structure comprises slightly distorted $\mathrm{AgO}_{4}$ subunits, with the $d^{8} \mathrm{Ag}(\mathrm{III})$ ions possessing an approximate square planar coordination to four oxygen atoms [Fig. 4(b)], as expected (a)

(b)

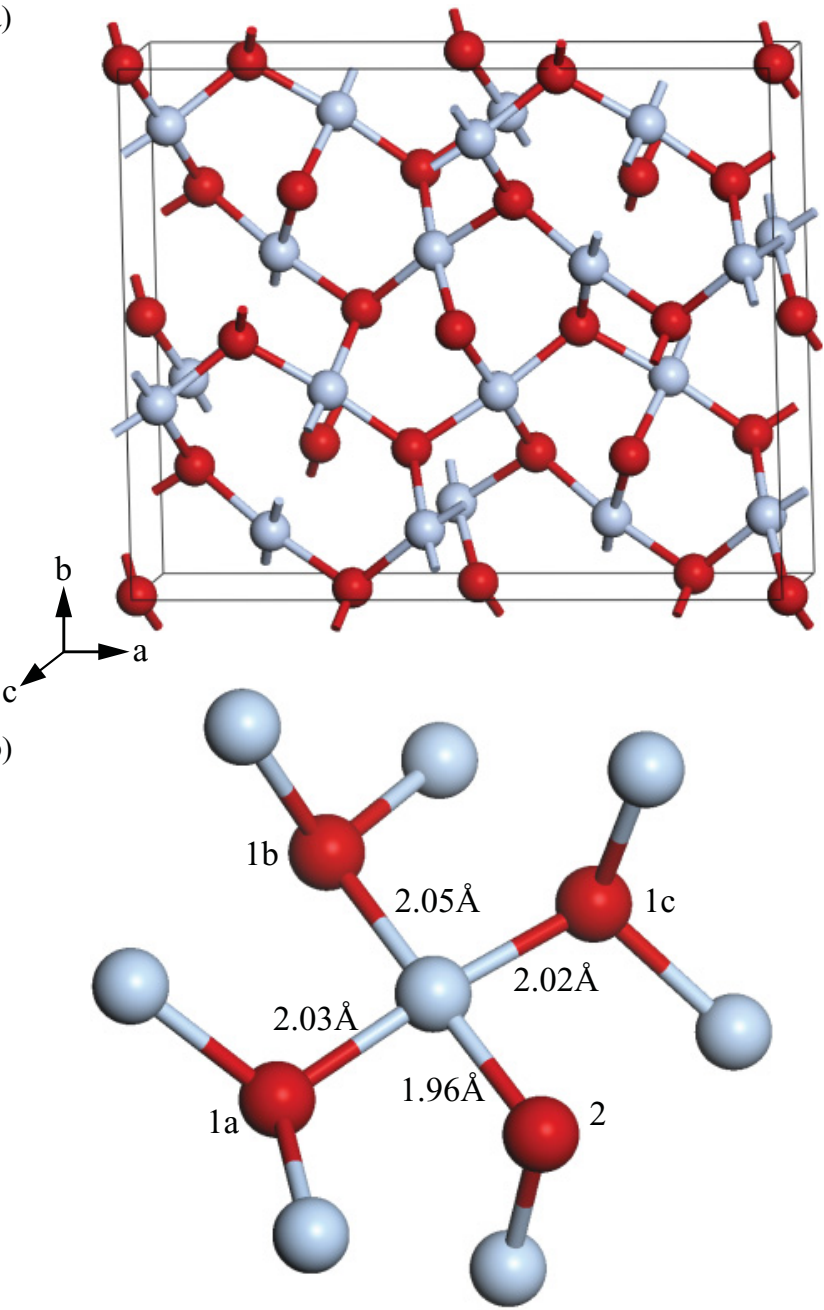

FIG. 4. (Color online) Atomic structure of (a) the unit cell of $\mathrm{Ag}_{2} \mathrm{O}_{3}$ and (b) the coordination environment around a silver atom, with bond distances from the experimental structure (Ref. 7). Silver (III) atoms are colored light blue (light gray) and oxygen atoms are colored red (dark gray).

due to crystal-field effects. ${ }^{89}$ Three of the oxygen atoms are bonded to three silver atoms, labeled $\mathrm{O}_{1 a}, \mathrm{O}_{1 b}$, and $\mathrm{O}_{1 c}$. The fourth oxygen atom, labeled $\mathrm{O}_{2}$, is bound to only two silver atoms, giving rise to the slight distortion of the square planar environment. The calculated lattice vectors and bond lengths, along with experimental values, ${ }^{7}$ are given in Table II. The HSE06 method is seen to perform noticeably better than GGA, reproducing the lattice constants to within $2.8 \%$ and the bond lengths to within $0.7 \%$. HF gives an even better reproduction of lattice vectors, being within $1.6 \%$, although the bond lengths are mainly underestimated, with some being up to $2.1 \%$ too small. All three methods show an expansion in the $c$ vector, relative to the $a$ and $b$ vectors, which is not reflected in the predicted $\mathrm{Ag}-\mathrm{O}$ bond lengths and is larger than typically seen for GGA/HSE06/HF calculations. From the structure, the $c$ vector appears to be influenced by Ag-Ag interactions in particular, rather than an Ag-O bond, and therefore this interaction may give rise to the unexpected expansion. This will be further discussed in Sec. IV. 
TABLE II. Experimental lattice vectors and bond lengths for $\mathrm{Ag}_{2} \mathrm{O}_{3}$ with those calculated using GGA, HSE06, and HF methods. Percentage changes to experiment are given in parentheses and all values are in $\AA$, except for the cell volume, which has units of $\AA^{3}$.

\begin{tabular}{|c|c|c|c|c|}
\hline Property & GGA & HSE06 & $\mathrm{HF}$ & Experiment (Ref. 7) \\
\hline$a$ & $\begin{array}{c}13.096 \\
(1.8)\end{array}$ & $\begin{array}{c}12.964 \\
(0.7)\end{array}$ & $\begin{array}{c}12.930 \\
(0.5)\end{array}$ & 12.869 \\
\hline$b$ & $\begin{array}{c}10.697 \\
(2.0)\end{array}$ & $\begin{array}{c}10.609 \\
(1.1)\end{array}$ & $\begin{array}{c}10.610 \\
(0.8)\end{array}$ & 10.490 \\
\hline$c$ & $\begin{array}{l}3.834 \\
(4.6)\end{array}$ & $\begin{array}{l}3.767 \\
(2.8)\end{array}$ & $\begin{array}{c}3.722 \\
(1.6)\end{array}$ & 3.664 \\
\hline Volume & $\begin{array}{c}537.05 \\
(8.7)\end{array}$ & $\begin{array}{c}518.06 \\
(4.8)\end{array}$ & $\begin{array}{c}510.61 \\
(3.3)\end{array}$ & 494.12 \\
\hline $\mathrm{Ag}-\mathrm{O}_{1 a}$ & $\begin{array}{l}2.077 \\
(2.4)\end{array}$ & $\begin{array}{c}2.037 \\
(0.4)\end{array}$ & $\begin{array}{c}2.011 \\
(-0.9)\end{array}$ & 2.029 \\
\hline $\mathrm{Ag}-\mathrm{O}_{1 b}$ & $\begin{array}{l}2.089 \\
(2.1)\end{array}$ & $\begin{array}{c}2.060 \\
(0.7)\end{array}$ & $\begin{array}{c}2.044 \\
(-0.1)\end{array}$ & 2.046 \\
\hline $\mathrm{Ag}-\mathrm{O}_{1 c}$ & $\begin{array}{l}2.056 \\
(1.7)\end{array}$ & $\begin{array}{c}2.014 \\
(-0.4)\end{array}$ & $\begin{array}{c}1.980 \\
(-2.0)\end{array}$ & 2.021 \\
\hline $\mathrm{Ag}-\mathrm{O}_{2}$ & $\begin{array}{l}1.999 \\
(1.9)\end{array}$ & $\begin{array}{l}1.958 \\
(-0.2)\end{array}$ & $\begin{array}{c}1.919 \\
(-2.1)\end{array}$ & 1.961 \\
\hline
\end{tabular}

The band structures calculated with the GGA and HSE06 functionals are given in Fig. 5. In comparison to GGA, the effect of the hybrid-DFT method can be seen to shift the $\mathrm{CB}$ up in energy relative to the VB, increasing the band gap. The valence band is also seen to be broadened slightly in the HSE06 calculation, relative to the GGA method. Although the two band structures are similar in structure, the location of the VBM is different. For the GGA-calculated band structure [Fig. 5(a)], the VBM is seen on the line between $L$ and $\Gamma$. However, for HSE06 [Fig. 5(b)], the VBM is seen to occur in two locations, one between $\Gamma-Z$ and the other between $X$ and $Y$. The CBMs for GGA and HSE06 are both located between $Z$ and $L$, giving indirect band gaps of 0.5 and $1.9 \mathrm{eV}$ for the two methods, respectively. The smallest direct band gaps for GGA and HSE06 are 0.6 and $2.0 \mathrm{eV}$, respectively, located along the $Z-L$ line in both cases. The band structure calculated using HF (not shown) is very similar in structure to those determined using GGA and HSE06. As with the HSE06 band structure, the HF VBM is found along the $X-Y$ line but the CBM is seen to differ. The CBM with HF is instead found along the $X-Y$ line, at a different position to the VBM, giving an indirect band gap. The band gaps are significantly overestimated, as expected, with values of 10.29 and $10.30 \mathrm{eV}$ for the indirect and direct fundamental band gaps. The only previously calculated band gap is from the DFT study of Burdett and Sevov. ${ }^{45}$ From their calculated EDOS, the band gap is estimated to be $0.96 \mathrm{eV}$, which is similar to our GGA value, albeit slightly higher due to their use of a different functional (the local density approximation).

The EDOS and PEDOS are shown for $\mathrm{Ag}_{2} \mathrm{O}_{3}$ in Fig. 6. with $\mathrm{Ag}_{2} \mathrm{O}$, the valence band is dominated by $\mathrm{Ag} 4 d$ and $\mathrm{O}$ $2 p$ states. The valence band can be split into three regions. Region I is seen to be mixed $\mathrm{Ag} 4 d$ and $\mathrm{O} 2 p$ (predominantly $\mathrm{O}_{1}$ ) states, with a minor contribution from the $\mathrm{Ag} 5 s$ states. The Ag $4 d$ states increase in dominance through region II, reaching a maximum near to the boundary with region III. The
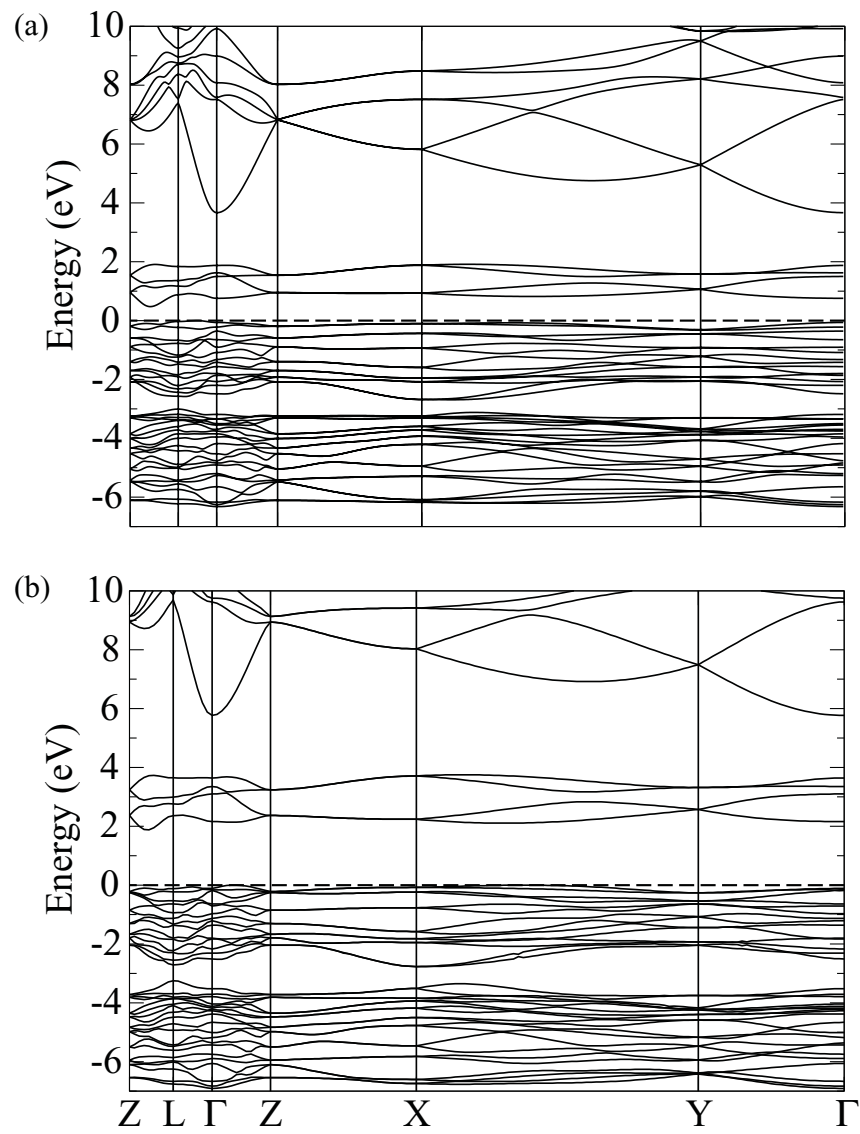

FIG. 5. Calculated band structure for $\mathrm{Ag}_{2} \mathrm{O}_{3}$ using the (a) GGA and (b) HSE06 functional. The top of the valence band in set to $0 \mathrm{eV}$.

opposite is true for the $\mathrm{O}_{1} 2 p$ states, which can be seen to diminish throughout the region. Region III comprises the top of the $\mathrm{VB}$ and, as region I, is mainly composed of mixed $\mathrm{Ag} 4 d$ and $\mathrm{O} 2 p$ states, with minor contributions from the $\mathrm{Ag} 5 s$ and $p$. In comparison to $\mathrm{Ag}_{2} \mathrm{O}$, this $\mathrm{Ag} 5 s$ and $p$ contribution to the VBM occurs over a greater energy range. The $\mathrm{O} 2 p$ states in region III differ for the two types of coordination. While the $\mathrm{O}_{1}$ $2 p$ states are seen to be equally spread throughout the region, those from the $\mathrm{O}_{2} 2 p$ are concentrated at higher energy, near to the VBM. The conduction band is split into two regions, IV and V. Region IV contains the empty Ag $4 d$ states, which are mixed with $\mathrm{O} 2 p$ states, and is then separated by a gap of $2.0 \mathrm{eV}$ from region $\mathrm{V}$, which consists of $\mathrm{Ag} 5 s$ and $p$ and $\mathrm{O} 2 p$ states.

The calculated EDOS, as well as the PEDOS, is consistent with previous work, in terms of both general structure and relative peak positions..$^{45} \mathrm{It}$ is also qualitatively similar to that calculated for the isostructural $\mathrm{Au}_{2} \mathrm{O}_{3} .{ }^{97}$ As HSE06 was seen to perform better for $\mathrm{Ag}_{2} \mathrm{O}$, widening the $\mathrm{VB}$ and increasing the band gap to values in closer agreement to experiment, it is therefore also likely to give more accurate results for $\mathrm{Ag}_{2} \mathrm{O}_{3}$.

\section{Silver (I,III) oxide, AgO}

$\mathrm{AgO}$ is known to crystallize in both monoclinic ${ }^{9}$ and tetragonal ${ }^{98}$ forms, with the former being the most commonly found and studied. The monoclinic structure, space group 


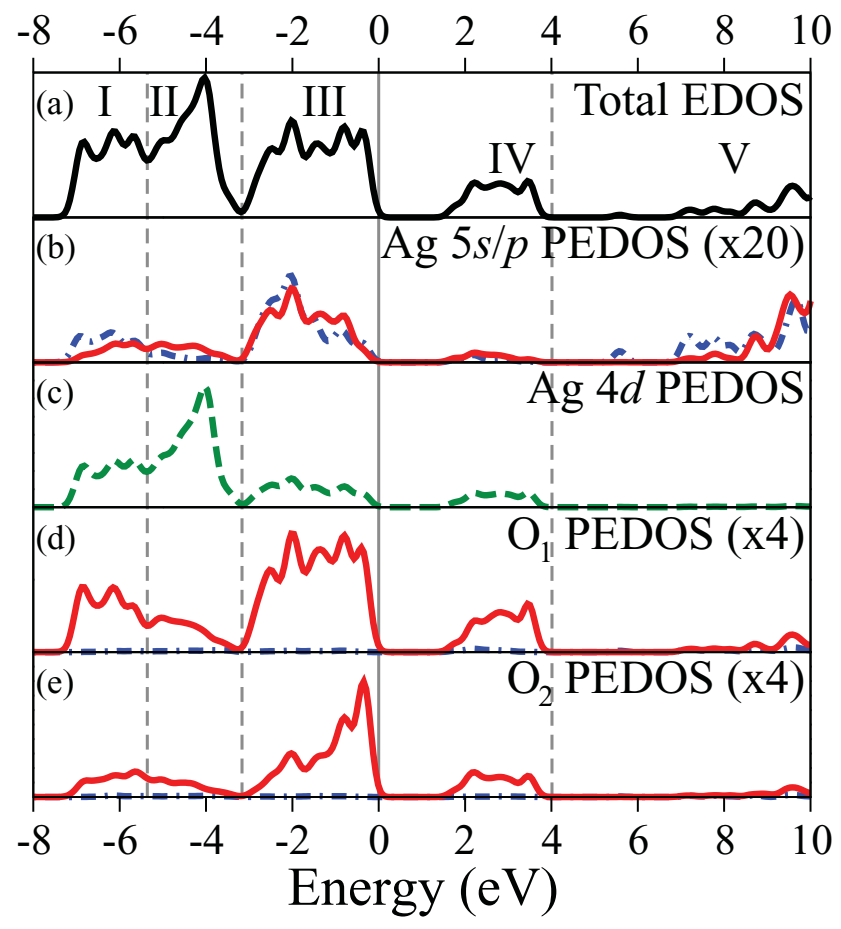

- - $s$ states

$p$ states $--d$ states

FIG. 6. (Color online) HSE06-calculated electronic density of states for $\mathrm{Ag}_{2} \mathrm{O}_{3}$. (a) Total EDOS, (b) $\mathrm{Ag} 5 \mathrm{~s}$ and $5 p$ PEDOS, (c) Ag $4 d$ PEDOS, (d) $\mathrm{O}_{1}$ PEDOS, and (e) $\mathrm{O}_{2}$ PEDOS, where $\mathrm{O}_{1}$ is a combination $\mathrm{O}_{1 a}, \mathrm{O}_{1 b}$, and $\mathrm{O}_{1 c}$ states. The $s, p$, and $d$ states are colored blue (dashed-dotted), red (dashed), and green (solid), respectively. The Fermi energy is represented by the vertical solid gray line, which has been set to $0 \mathrm{eV}$.

$P 12_{1} / c 1$, possesses two different coordination environments, and associated oxidation states, for the silver ions, as shown in Fig. 7, which were previously shown to be $\operatorname{Ag}(\mathrm{I})$ and $\mathrm{Ag}(\mathrm{III})$ valences. ${ }^{49}$ The $\mathrm{Ag}(\mathrm{I})$ ions have a linear coordination to oxygen with an Ag-O bond distance of $2.16 \AA$. The $\mathrm{Ag}(\mathrm{III})$ ions, however, have slightly distorted square planar environments, with bond distances of 2.02 and $2.03 \AA$, and bond angles of $88.6^{\circ}$ and $91.4^{\circ}$. From a structural point of view, similarities can be seen between the structure of $\mathrm{AgO}$ with the corresponding $\mathrm{Ag}(\mathrm{I})$ and $\mathrm{Ag}(\mathrm{III})$ environments seen in $\mathrm{Ag}_{2} \mathrm{O}$ and $\mathrm{Ag}_{2} \mathrm{O}_{3}$, Figs. 1 and 4, respectively. Although similar $\mathrm{Ag}$ (III)-O bond distances are seen in both $\mathrm{AgO}$ and $\mathrm{Ag}_{2} \mathrm{O}_{3}$, the $\mathrm{Ag}(\mathrm{I})-\mathrm{O}$ bond distances are extended in $\mathrm{AgO}$, compared to the $2.05 \AA$ seen in $\mathrm{Ag}_{2} \mathrm{O}$.

Minimization of $\mathrm{AgO}$ was first conducted using the GGA, HSE06, and HF methods, with the optimized structural parameters and bond lengths provided in Table III. As we have previously reported, ${ }^{49}$ the GGA and HSE06/HF methodologies predict different minimum energy structures. The HSE06 approach minimizes the structure to within reasonable agreement with experiment, with measured parameters varying from experiment by less than $3.3 \%$. The HF method predicts the same structure as HSE06 but is a little more distorted, with errors in the lattice vectors of up to $5.8 \%$ greater than experiment. This distortion is seen to be caused by an overestimated $\mathrm{Ag}(\mathrm{I})-\mathrm{O}$ bond length and underestimated $\mathrm{Ag}(\mathrm{III})-\mathrm{O}$ (a)

(b)

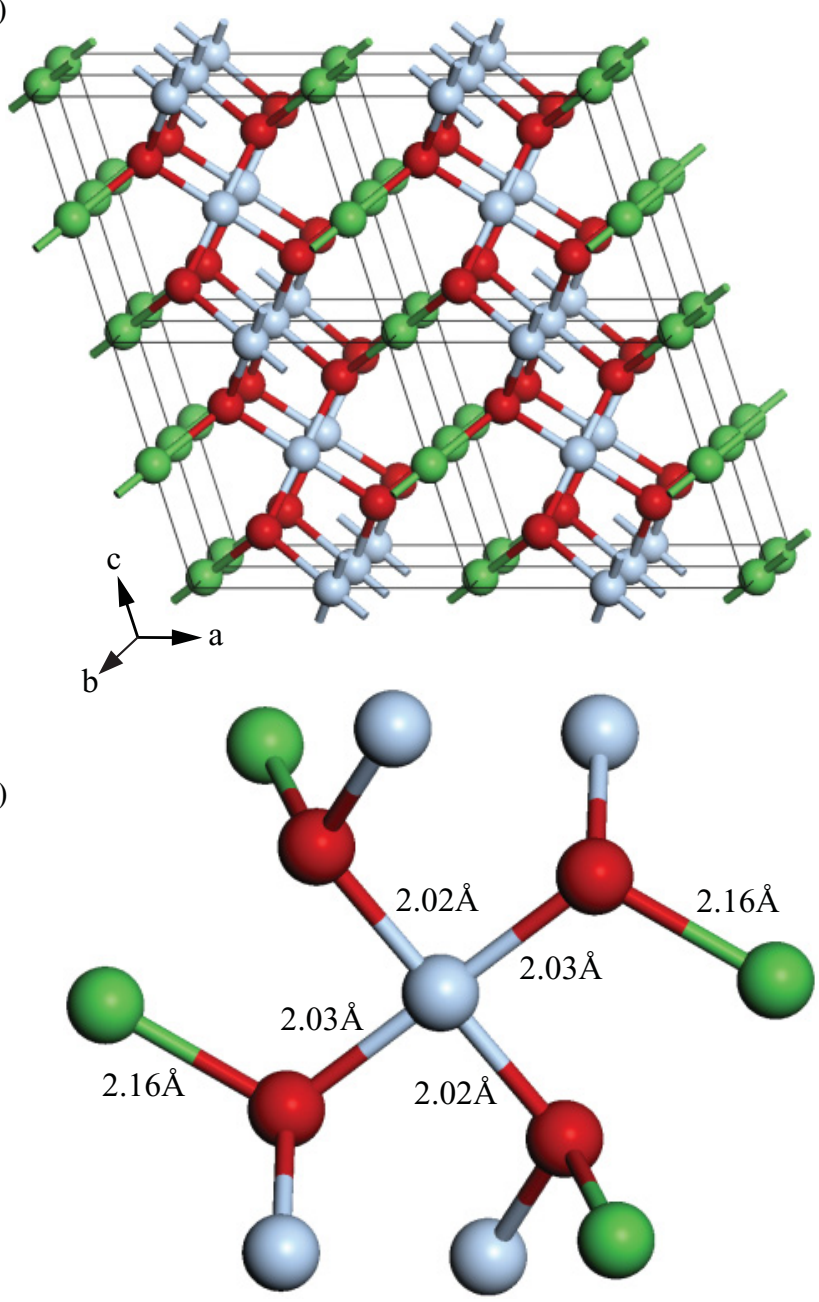

FIG. 7. (Color online) Atomic structure of (a) the unit cell of $\mathrm{AgO}$, grown $2 \times 2 \times 2$ for clarity, and (b) the coordination environment around an $\mathrm{Ag}(\mathrm{III})$ ion, with corresponding bond lengths. Green (medium gray), light blue (light gray), and red (dark gray) spheres represent the $\mathrm{Ag}(\mathrm{I}), \mathrm{Ag}(\mathrm{III})$, and oxygen atoms, respectively. See text for details of bond angles around the $\mathrm{Ag}(\mathrm{III})$ ion.

bonds. The GGA method, however, fails to capture the mixed valence character of this structure, with the minimized cell possessing equivalent silver atoms. The generated structure [Fig. 8(a)] shares similarities with the $\mathrm{CuO}$ structure, which formally possesses $\mathrm{Cu}$ (II) ions. ${ }^{99}$ For comparison, Figs. 8(b) and 8(c) show the basic structural motif of a metal ion in the GGA-predicted $\mathrm{AgO}$ and experimental $\mathrm{CuO}$ structures, respectively. As can be seen, a similar bonding pattern is given by both materials, albeit with the AgO structure possessing a greater amount of symmetry in the square planar environment around the Ag ions. This is most likely due to the shorter $\mathrm{Cu}-\mathrm{O}$ bond length causing more strain, which is alleviated by the distortion away from the symmetric coordination.

The probable cause of the failure of GGA is the selfinteraction error that is present in standard DFT approaches, which favors the delocalization of charge giving rise to equivalent silver atoms. To assess the ability of the GGA $+U$ approach to predict the correct $\mathrm{Ag}(\mathrm{I}, \mathrm{III})$ mixed valence, we have applied $U$ values ranging between 1 and $7 \mathrm{eV}$ to 
TABLE III. Experimental lattice vectors and bond lengths for AgO with those calculated using GGA GGA + U, and HSE06 methods. For GGA $+U$ calculations, where $U=5$ or $6 \mathrm{eV}$, values for both $\mathrm{Ag}(\mathrm{II}) \mathrm{O}$ and $\mathrm{Ag}(\mathrm{I}, \mathrm{III}) \mathrm{O}$ structure types are quoted. Percentage changes to experiment are given in parentheses and all values are in $\AA$, except for the cell volume, which has units of $\AA^{3}$.

\begin{tabular}{|c|c|c|c|c|c|c|c|c|}
\hline \multirow[b]{2}{*}{ Property } & \multirow[b]{2}{*}{ GGA } & \multicolumn{2}{|c|}{$U=5 \mathrm{eV}$} & \multicolumn{2}{|c|}{$U=6 \mathrm{eV}$} & \multirow[b]{2}{*}{ HSE06 } & \multirow[b]{2}{*}{$\mathrm{HF}$} & \multirow[b]{2}{*}{ Experiment (Ref. 9) } \\
\hline & & $\mathrm{Ag}(\mathrm{II}) \mathrm{O}$ & $\mathrm{Ag}(\mathrm{I}, \mathrm{III}) \mathrm{O}$ & $\mathrm{Ag}(\mathrm{II}) \mathrm{O}$ & $\mathrm{Ag}(\mathrm{I}, \mathrm{III}) \mathrm{O}$ & & & \\
\hline$a$ & $\begin{array}{c}4.738 \\
(-19.1)\end{array}$ & $\begin{array}{c}4.777 \\
(-18.5)\end{array}$ & $\begin{array}{l}5.718 \\
(-2.4)\end{array}$ & $\begin{array}{c}4.804 \\
(-18.0)\end{array}$ & $\begin{array}{l}5.727 \\
(-2.2)\end{array}$ & $\begin{array}{l}5.934 \\
(1.3)\end{array}$ & $\begin{array}{l}5.957 \\
(1.7)\end{array}$ & 5.859 \\
\hline$b$ & $\begin{array}{l}4.616 \\
(32.5)\end{array}$ & $\begin{array}{l}4.542 \\
(30.4)\end{array}$ & $\begin{array}{c}3.669 \\
(5.3)\end{array}$ & $\begin{array}{l}4.510 \\
(29.4)\end{array}$ & $\begin{array}{c}3.665 \\
(5.2)\end{array}$ & $\begin{array}{c}3.599 \\
(3.3)\end{array}$ & $\begin{array}{c}3.689 \\
(5.8)\end{array}$ & 3.484 \\
\hline$c$ & $\begin{array}{l}5.601 \\
(1.8)\end{array}$ & $\begin{array}{l}5.637 \\
(2.5)\end{array}$ & $\begin{array}{l}5.570 \\
(1.3)\end{array}$ & $\begin{array}{l}5.640 \\
(2.5)\end{array}$ & $\begin{array}{l}5.562 \\
(1.1)\end{array}$ & $\begin{array}{l}5.551 \\
(0.9)\end{array}$ & $\begin{array}{c}5.529 \\
(0.5)\end{array}$ & 5.500 \\
\hline Volume & $\begin{array}{c}122.50 \\
(14.4)\end{array}$ & $\begin{array}{l}122.31 \\
(14.2)\end{array}$ & $\begin{array}{c}113.19 \\
(5.7)\end{array}$ & $\begin{array}{l}122.20 \\
(14.1)\end{array}$ & $\begin{array}{c}113.19 \\
(5.7)\end{array}$ & $\begin{array}{c}113.21 \\
(5.7)\end{array}$ & $\begin{array}{l}118.46 \\
(10.6)\end{array}$ & 107.07 \\
\hline $\mathrm{Ag}(\mathrm{I})-\mathrm{O}$ & $\begin{array}{c}2.167 \\
(0.3)\end{array}$ & $\begin{array}{c}2.168 \\
(0.3)\end{array}$ & $\begin{array}{c}2.224 \\
(2.9)\end{array}$ & $\begin{array}{c}2.168 \\
(0.3)\end{array}$ & $\begin{array}{c}2.242 \\
(3.7)\end{array}$ & $\begin{array}{c}2.155 \\
(-0.3)\end{array}$ & $\begin{array}{c}2.311 \\
(6.9)\end{array}$ & 2.161 \\
\hline $\mathrm{Ag}(\mathrm{IIII})-\mathrm{O}_{\text {short }}$ & $\begin{array}{c}2.167 \\
(7.1)\end{array}$ & $\begin{array}{l}2.168 \\
(7.2)\end{array}$ & $\begin{array}{c}2.069 \\
(2.3)\end{array}$ & $\begin{array}{c}2.168 \\
(7.2)\end{array}$ & $\begin{array}{c}2.066 \\
(2.1)\end{array}$ & $\begin{array}{c}2.015 \\
(-0.4)\end{array}$ & $\begin{array}{l}1.985 \\
(-1.9)\end{array}$ & 2.023 \\
\hline $\mathrm{Ag}(\mathrm{III})-\mathrm{O}_{\text {long }}$ & $\begin{array}{l}2.167 \\
(6.9)\end{array}$ & $\begin{array}{c}2.168 \\
(6.9)\end{array}$ & $\begin{array}{c}2.069 \\
(2.0)\end{array}$ & $\begin{array}{c}2.168 \\
(6.9)\end{array}$ & $\begin{array}{c}2.068 \\
(2.0)\end{array}$ & $\begin{array}{l}2.018 \\
(-0.5)\end{array}$ & $\begin{array}{l}1.986 \\
(-2.1)\end{array}$ & 2.028 \\
\hline
\end{tabular}

the $\mathrm{Ag} 4 d$ states. Both the experimental $[\mathrm{Ag}(\mathrm{I} / \mathrm{III}) \mathrm{O}]$ and GGA-predicted $[\mathrm{Ag}(\mathrm{II}) \mathrm{O}]$ structures were modeled with this method, calculating the predicted energy as a function of the unit cell volume, ranging between 103.89 and $131.17 \AA^{3}$. The energy-volume curves for these different approaches are provided in Fig. 9. No constraints other than allowing the lattice vectors and angles of the unit cell to vary under a constant total volume were applied to the systems. For all $\mathrm{Ag}(\mathrm{II}) \mathrm{O}$ simulations the structure was maintained. However, as the volume increases, a structural change from the $\mathrm{Ag}(\mathrm{I}, \mathrm{III}) \mathrm{O}$ to the $\mathrm{Ag}(\mathrm{II}) \mathrm{O}$ unit cell was observed with the $\mathrm{GGA}+U$ method. Therefore, to give an estimate of the energy for the next volume, the unit-cell dimensions and angles were scaled and only the atomic coordinates were allowed to relax. These calculations are those termed "predicted energy for $\mathrm{Ag}(\mathrm{I}, \mathrm{III}) \mathrm{O}$ structure" in Fig. 9 and are shown as open circles.

The GGA method is clearly seen to predict the erroneous $\mathrm{Ag}(\mathrm{II}) \mathrm{O}$ structure as being the lowest in energy at all modeled volumes. For the GGA $+U$ method a number of observations can be identified. First, for a $U$ value of $1 \mathrm{eV}$, it was not possible to obtain any energies for the $\mathrm{Ag}(\mathrm{I}, \mathrm{III}) \mathrm{O}$ structure type as the structure always reverted to the $\mathrm{Ag}(\mathrm{II}) \mathrm{O}$ structure. Second, as the $U$ value is increased, the energy of the $\operatorname{Ag}(\mathrm{I}, \mathrm{III}) \mathrm{O}$ structure is stabilized, relative to the $\mathrm{Ag}(\mathrm{II}) \mathrm{O}$ structure, with a $U$ value of $6 \mathrm{eV}$ being the first to correctly predict the $\mathrm{Ag}(\mathrm{I}, \mathrm{III}) \mathrm{O}$ structure as the lowest in energy. This suggests that the minimum value of $U$ required to predict the correct ground-state electronic structure must, at least, be greater than $5 \mathrm{eV}$. Although this study simply considers the effect of $U$ and does not attempt to determine an accurate value of $U$ for this system, this is similar to that reported for $\mathrm{Cu}$, where a $U$ value of $5.2 \mathrm{eV}$ was used for $\mathrm{Cu}(\mathrm{I})$ in both oxide $\mathrm{e}^{100}$ and delafossite ${ }^{101}$ materials, providing close agreement to experiment for structural and electronic data. However, it should be noted that at large volumes, greater than $\sim 122 \AA^{3}$, a $U$ value of $7 \mathrm{eV}$ still predicts the $\mathrm{Ag}(\mathrm{II}) \mathrm{O}$ structure as being the lowest in energy. The HSE06 simulations, on the other hand, show the correct prediction of the $\mathrm{Ag}(\mathrm{I}, \mathrm{III})$ structure as the minimum in energy at all modeled volumes.

To allow comparison between the different methods, the predicted structural parameters for the minimum energy $\mathrm{Ag}(\mathrm{I}, \mathrm{III}) \mathrm{O}$ and $\mathrm{Ag}(\mathrm{II}) \mathrm{O}$ structures are given for $U$ values of 5 and $6 \mathrm{eV}$, alongside those determined with GGA and HSE06, in Table III. The GGA $+U \operatorname{Ag}(\mathrm{II}) \mathrm{O}$ structures are similar to that seen for the GGA calculation, albeit with a slightly reduced volume. For the mixed valence $\operatorname{Ag}(\mathrm{I}, \mathrm{III}) \mathrm{O}$ structure, although GGA $+U$ predicts a similar volume to the HSE06 calculation, the monoclinic cell is considerably more distorted in the $a$ and $b$ lattice vectors. In addition, the $\mathrm{Ag}(\mathrm{I})-\mathrm{O}$ bond lengths are significantly overestimated. This increased distortion and longer bond lengths may be a consequence of applying the same $U$ value to the $4 d$ states, regardless of the silver valence state and coordination environment, rather than using different values for $\operatorname{Ag}(\mathrm{I})$ and $\operatorname{Ag}(\mathrm{III})$ species. Wang et al. have previously shown that different $U$ values should be applied to different oxidation states for a range of $3 d$ oxide materials. ${ }^{102}$ However, a more extensive assessment of the application of $\mathrm{GGA}+U$ to the $\mathrm{AgO}$ system would be required to clarify this.

The calculated band structures using the GGA and HSE06 methods are detailed in Fig. 10. The GGA band structure shown is that for the $\mathrm{Ag}(\mathrm{I}, \mathrm{III}) \mathrm{O}$ structure, despite it not being predicted as the lowest in energy, and erroneously is predicted to be semimetallic. For the HSE06-determined band structure, the VBM is found at the $\Gamma$ point, whereas the CBM is present along the line from $\Gamma$-D, giving an indirect fundamental band gap of $1.0 \mathrm{eV}$. The smallest observable direct band gap has a value of $1.2 \mathrm{eV}$, which is also located along the $\Gamma$-D direction. Experimentally, an optical band gap of 1.0-1.1 eV (Refs. 103, 104 ) is reported, which is comparable to our theoretical direct fundamental band gap. The band structure calculated with HF (not shown) is qualitatively similar to that calculated with 
(a)

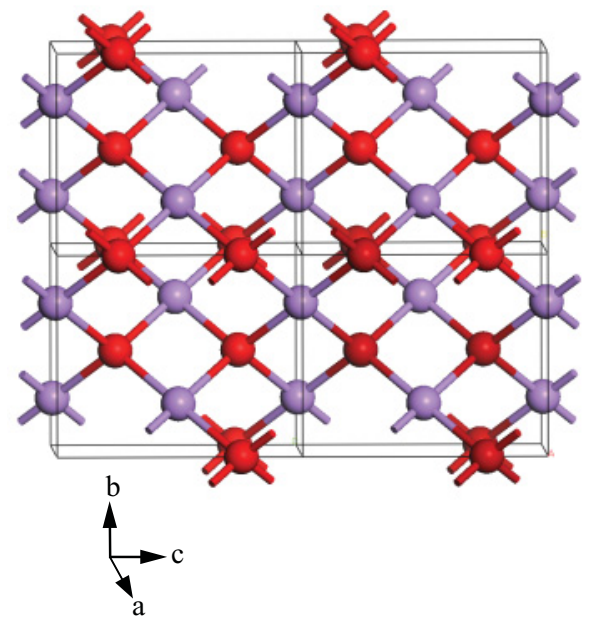

(b)

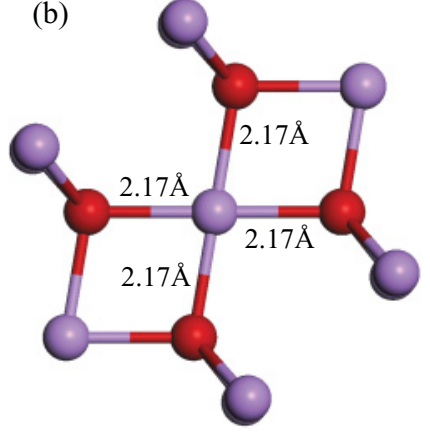

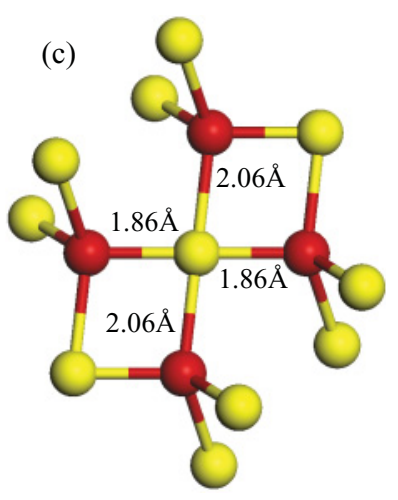

FIG. 8. (Color online) Schematic showing (a) the minimized unit cell structure of $\mathrm{AgO}$ as predicted using a GGA method, grown $1 \times 2 \times 2$ for clarity. Ag ions are colored purple (medium gray) and $\mathrm{O}$ ions are red (dark gray). The bonding environment of the silver ions, with corresponding bond lengths, is detailed in (b), while (c) shows the corresponding bonding environment in the experimental structure of $\mathrm{Cu}(\mathrm{II}) \mathrm{O}$ (Ref. 99), where copper ions are colored yellow (light gray).

HSE06. However, as seen for the other oxides, the band gap is significantly overestimated. The smallest indirect and direct fundamental band gaps were found to be 9.61 and $9.62 \mathrm{eV}$, respectively.

The EDOS and PEDOS for AgO, calculated with HSE06, can be seen in Fig. 11. The VB can be represented by four regions (I-IV) and the $\mathrm{CB}$ by two regions (V-VI). The first region is a result of mixed $\mathrm{O} 2 p$ and $\mathrm{Ag}$ (III) $4 d$ states. Region II is seen to be a combination of $4 d$ states from both $\mathrm{Ag}$ environments, $\operatorname{Ag}($ III) $s$ and $p$ states and $\mathrm{O} 2 p$ states. The $\mathrm{Ag}(\mathrm{I})$ $4 d$ states are more dominant than those of $\mathrm{Ag}(\mathrm{III})$ though, and reach a maximum $\sim 2.8 \mathrm{eV}$ below the VBM. The VBM, region IV, consists of mixed $\operatorname{Ag}(\mathrm{I}) 4 d$ and $\mathrm{O} 2 p$ states, with a small contribution from the $\operatorname{Ag}(\mathrm{I}) 5 \mathrm{~s}$. The bottom of the conduction band, region $\mathrm{V}$, mainly comprises mixed $\mathrm{Ag}(\mathrm{III}) 4 d$ and $\mathrm{O} 2 p$ states. Region VI is seen to contain $\mathrm{Ag} 5 s$ and $p$ states.

The PEDOSs of the $\mathrm{Ag}(\mathrm{I})$ and $\mathrm{Ag}(\mathrm{III})$ in $\mathrm{AgO}$ have a number of similarities to those calculated for $\mathrm{Ag}_{2} \mathrm{O}$ and $\mathrm{Ag}_{2} \mathrm{O}_{3}$, respectively. The $4 d$ peaks in $\mathrm{AgO}$ are seen to be broader in comparison to their counterparts in the single-valence binary oxides though, suggestive of a stronger interaction between $\mathrm{Ag}$ and $\mathrm{O}$ species in the mixed-valence system. The $\mathrm{Ag}(\mathrm{I})$ ions in $\longrightarrow \mathrm{Ag}(\mathrm{I}, \mathrm{III}) \mathrm{O}$ Structure $\longrightarrow \mathrm{Ag}(\mathrm{II}) \mathrm{O}$ Structure

$\odot--\odot$ Predicted Energy for $\mathrm{Ag}(\mathrm{I}, \mathrm{III}) \mathrm{O}$ Structure

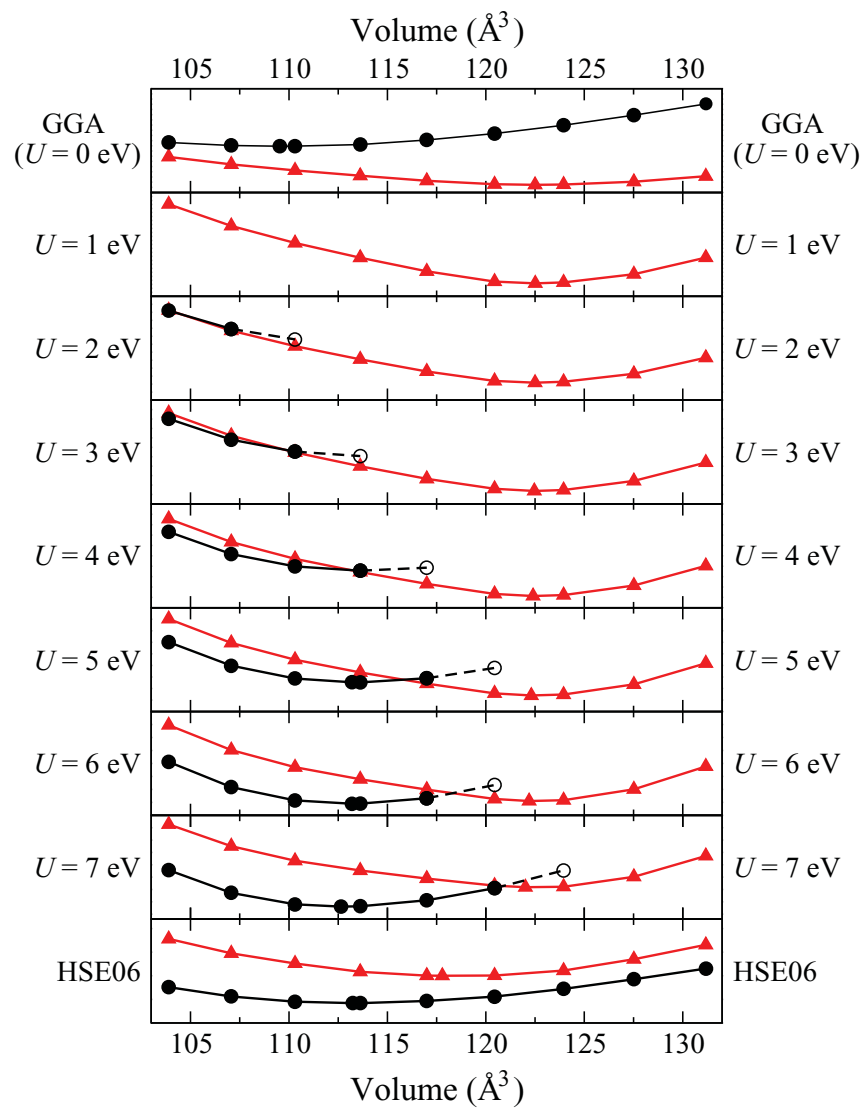

FIG. 9. (Color online) Energy-volume curves for AgO. The system was minimized as two different structures, namely, the experimental (Ref. 9) $\mathrm{Ag}(\mathrm{I}, \mathrm{III}) \mathrm{O}$ and GGA-predicted $\mathrm{Ag}(\mathrm{II}) \mathrm{O}$ structures. These are indicated by the black (solid circles) and red (triangles) lines, respectively. Dashed lines (open circles) represent calculations where the unit-cell dimensions and shapes were held fixed as full minimization resulted in a structural change. The simulations were trialled with GGA, GGA $+U(U$ varied from 1 to $7 \mathrm{eV})$, and HSE06 methodologies.

regions II-IV of the AgO PEDOS show a very similar structure to regions II-IV of the $\mathrm{Ag}_{2} \mathrm{O}$ PEDOS (Fig. 3), particularly with the VBM comprising mixed $\mathrm{Ag} 4 d, \mathrm{Ag} 5 s$, and O $2 p$ states.

For $\mathrm{Ag}_{2} \mathrm{O}_{3}$, region I of the $\mathrm{Ag}(\mathrm{III})$ and $\mathrm{O}$ PEDOS for $\mathrm{AgO}$ is similar in structure to a combination of regions I and II in the $\mathrm{Ag}_{2} \mathrm{O}_{3}$ PEDOS (Fig. 6). The top of the valence band (region III) for $\mathrm{Ag}_{2} \mathrm{O}_{3}$ shares similar features and composition to region III in the AgO PEDOS, being made up of a mix of $\operatorname{Ag}(\mathrm{III}) s$ and $p$ and $\mathrm{O} 2 p$ states. The distinct CBM structure is also very similar between $\mathrm{AgO}$ and $\mathrm{Ag}_{2} \mathrm{O}_{3}$, possessing the unoccupied $4 d$ states mixed with $\mathrm{O} 2 p$ states.

\section{Optical properties}

The calculated optical absorption spectra for the three materials, using HSE06, is shown in Fig. 12. According to the Tauc relation:

$$
\alpha h v=\operatorname{const}\left(h v-E_{\mathrm{g}}\right)^{n},
$$


(a)

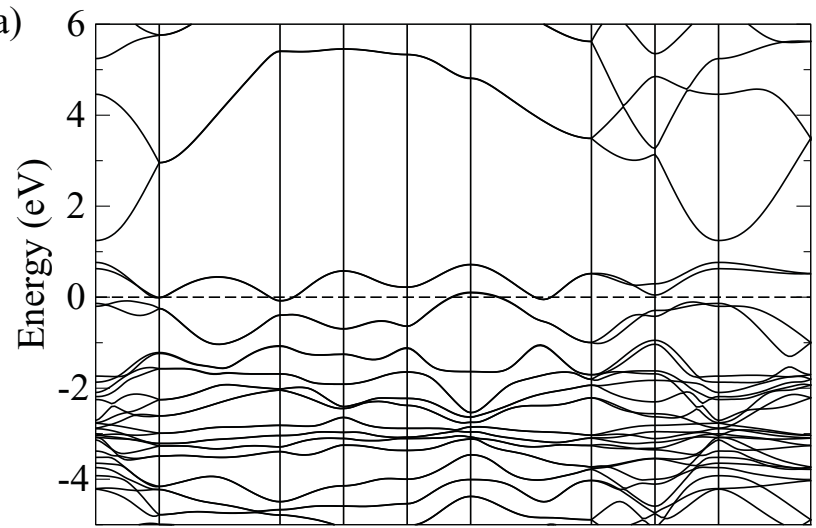

(b)

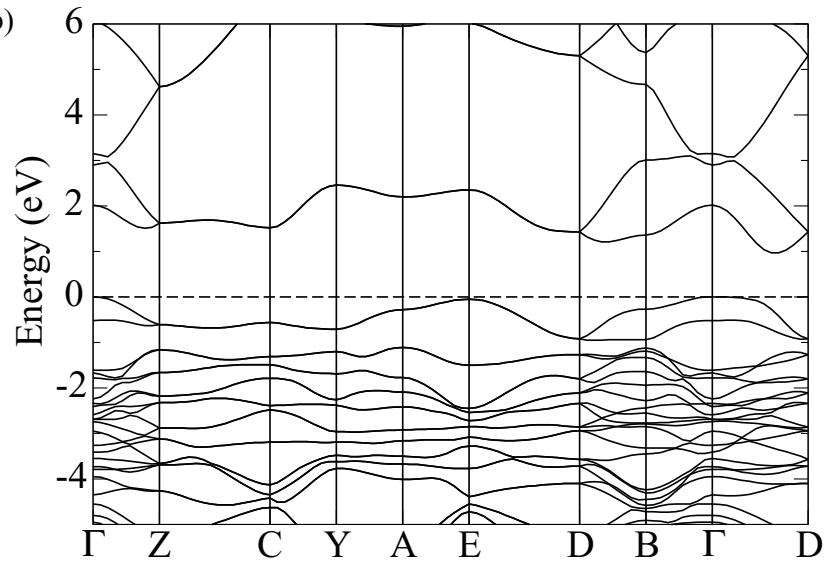

FIG. 10. Calculated band structure for AgO using the (a) GGA and (b) HSE06 functional. The top of the valence band in set to $0 \mathrm{eV}$, or, for GGA, the Fermi energy.

where $\alpha$ is the absorption coefficient, $h v$ is the photon energy, $E_{\mathrm{g}}$ is the optical gap, and $n$ is an index which depends on the nature of the electronic transition responsible for the absorption ( $1 / 2$ for an allowed direct transition). Therefore, the optical band gap can be obtained from a plot of $(\alpha h v)^{2}$ vs $h v$ by extrapolating $(\alpha h v)^{2}$ to zero. ${ }^{105-107}$

For both $\mathrm{AgO}$ and $\mathrm{Ag}_{2} \mathrm{O}_{3}$, the onset of optical absorption is seen to correspond to transitions from the VBM to CBM at the location of the direct fundamental band gaps. For $\mathrm{AgO}$, this onset occurs along the $\Gamma-D$ high-symmetry line, with a calculated optical band gap of $1.40 \mathrm{eV}$. This compares reasonably well with the experimental value of $1.0-1.1 \mathrm{eV} .{ }^{103,104}$ For $\mathrm{Ag}_{2} \mathrm{O}_{3}$, the onset of optical absorption occurs along the $Z$ - $L$ high-symmetry line and the calculated optical band gap is $2.13 \mathrm{eV}$.

For $\mathrm{Ag}_{2} \mathrm{O}$, the calculated optical band gap of $2.15 \mathrm{eV}$ does not correspond to the fundamental band gap of $1.1 \mathrm{eV}$. This is due to transitions at the $\Gamma$ point being symmetry disallowed, as is also seen for isostructural $\mathrm{Cu}_{2} \mathrm{O} .{ }^{108}$ Instead, the onset of optical absorption is seen to occur through transitions between the top of the VB and bottom of the CB away from $\Gamma$, in both the $X$ and $M$ directions. The calculated optical band gap also compares favorably with the experiment of Varkey and Fort, ${ }^{40}$ which reported a value of $2.25 \mathrm{eV}$.

Contrary to the work of Varkey and Fort, a recent study by Lyu et $a l .{ }^{41}$ on nanoparticles has reported an optical band gap

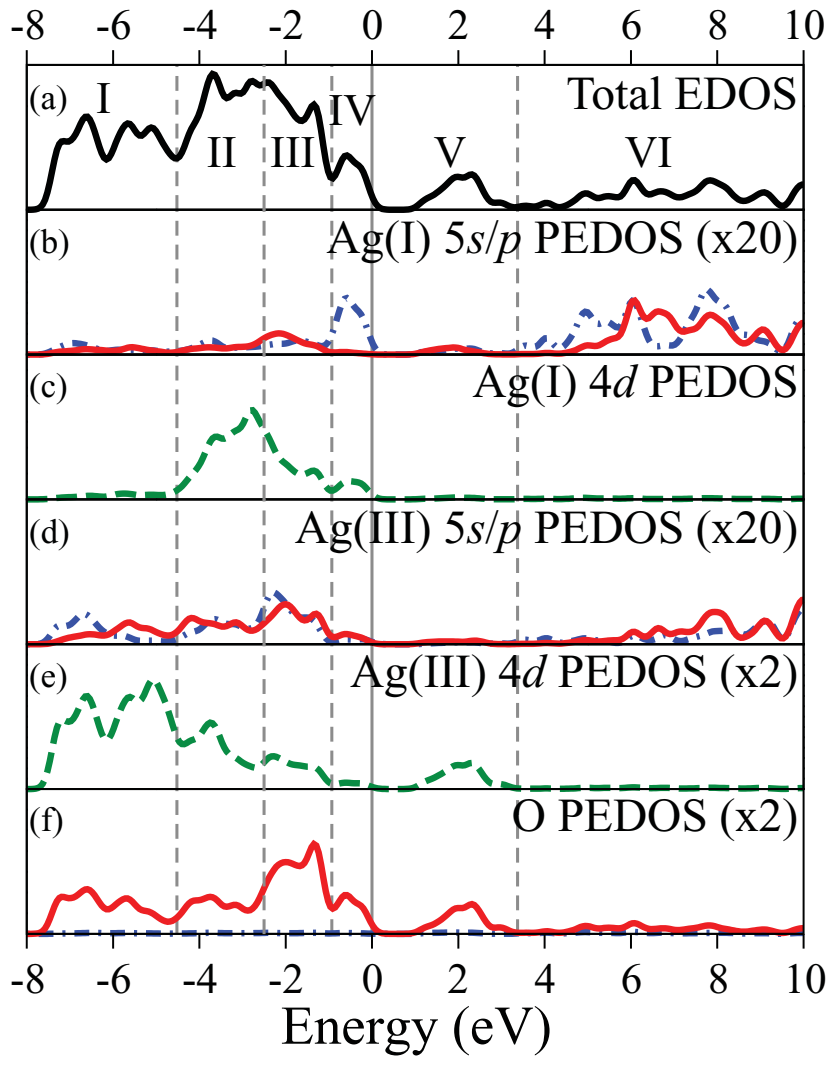

$\cdot-s$ states $-p$ states $--d$ states

FIG. 11. (Color online) HSE06-calculated electronic density of states for AgO. (a) Total EDOS, (b) $\mathrm{Ag}(\mathrm{I}) 5 s$ and $5 p$ PEDOS, (c) $\operatorname{Ag}(\mathrm{I}) 4 d$ PEDOS, (d) $\mathrm{Ag}$ (III) $5 s$ and $5 p$ PEDOS, (e) $\mathrm{Ag}$ (III) $4 d$ PEDOS, and (f) O PEDOS. The $s, p$, and $d$ states are colored blue (dashed-dotted), red (dashed), and green (solid), respectively. The Fermi energy is represented by the vertical solid gray line, which has been set to $0 \mathrm{eV}$.

of $1.46 \mathrm{eV}$, which is also in disagreement with our calculated value. As quantum confinement has been shown to affect the size of band gaps ${ }^{109}$ though, this questions whether the optical absorption of nanoparticles is representative of the bulk material. An optical band gap of $1.46 \mathrm{eV}$ was also reported by Ida et $a l .{ }^{42}$ based on the study of electrodeposited $\mathrm{Ag}_{2} \mathrm{O}$ films. However, caution should be taken with data from electrodeposited films, for example, questionable $n$-type conductivity was reported for the isostructural $\mathrm{Cu}_{2} \mathrm{O} \cdot{ }^{110-114}$ Experimental ${ }^{115}$ and computational ${ }^{67}$ studies have since suggested that the origin of this behavior is through the formation of an uncharacterized inversion layer on the surface of the film, which may possess some $\mathrm{Cu}$ (II) character. Although the formation of $\mathrm{Ag}(\mathrm{II})$ is unlikely for $\mathrm{Ag}_{2} \mathrm{O}$, this does raise concern over the exact stoichiometry, surface structure, and the resultant properties of thin films made through electrodeposition. Furthermore, Wei et al. have recently reported the presence of ordered silver vacancies in electrodeposited $\mathrm{Ag}_{x} \mathrm{O}$ nanostructures, although they made no measure of optical absorption. ${ }^{116}$

The calculated optical band gap of $\mathrm{AgO}, 1.40 \mathrm{eV}$, is much closer to those reported by Lyu et al. and Ida et al. Although this close agreement may simply be fortuitous, it could also suggest 


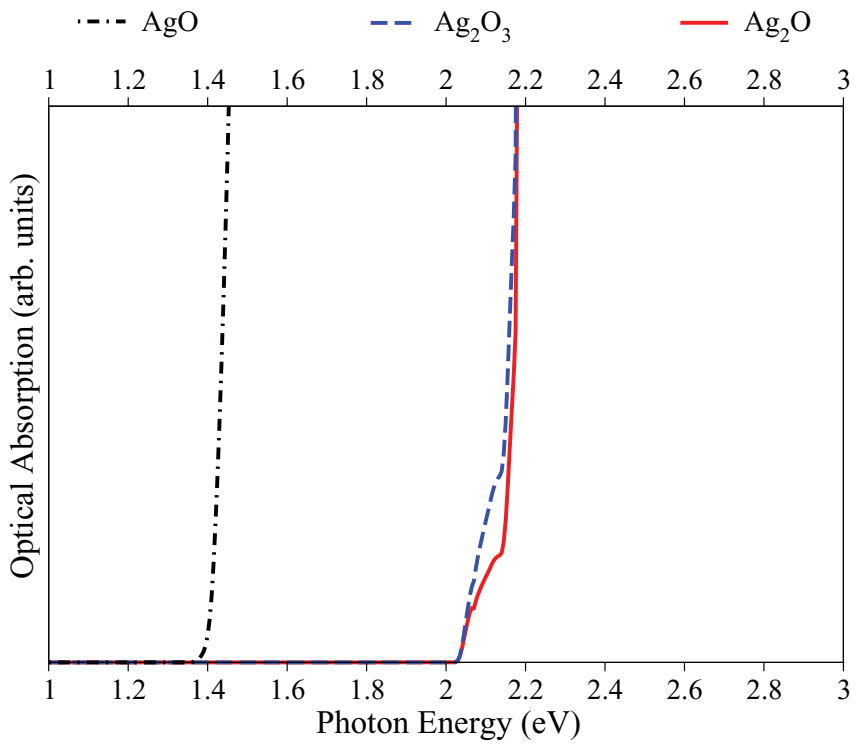

FIG. 12. (Color online) HSE06-calculated absorption spectra $(\alpha h v)^{2}$ for $\mathrm{AgO}$ (black/dashed-dotted), $\mathrm{Ag}_{2} \mathrm{O}_{3}$ (blue/dashed), and $\mathrm{Ag}_{2} \mathrm{O}$ (red/solid).

that the reported absorption does not originate from pure $\mathrm{Ag}_{2} \mathrm{O}$. Although further investigation is needed to fully address this discrepancy, it may result from some $\mathrm{AgO}$ impurities or silver-deficient $\mathrm{Ag}_{2} \mathrm{O}$.

\section{DISCUSSION OF CRYSTAL STRUCTURES}

For the silver oxides studied here, all three methods show deviations to experiment in the structural parameters. The deviations for the HF calculations are seen to differ substantially for each of the oxides. In $\mathrm{Ag}_{2} \mathrm{O}$, the lattice vectors are seen to be overestimated by $5.9 \%$. However, for $\mathrm{Ag}_{2} \mathrm{O}_{3}$, this large expansion is not seen, with lattice vectors being within $1.6 \%$ of experiment and $\mathrm{Ag}(\mathrm{III})-\mathrm{O}$ bond lengths being slightly underestimated. For $\mathrm{AgO}$, a mixed situation is seen, with the unit cell distorted so that the $b$ vector is $5.8 \%$ larger than experiment but the error in the $c$ vector is only $0.5 \%$. The $\mathrm{Ag}(\mathrm{I})-\mathrm{O}$ lengths are found to be $6.9 \%$ too large, whereas the $\mathrm{Ag}$ (III)-O bonds are on average $2.0 \%$ too small, which is the cause of the distortion in the unit cell. Aprà et al. previously used $\mathrm{HF}$ to model $\mathrm{AgCl}$ and found the lattice parameter to be overestimated by $7 \%,{ }^{117}$ which corresponds with that seen in this study for $\operatorname{Ag}(\mathrm{I})$ species. This overexpansion was attributed to interionic correlation effects present in $\operatorname{Ag}(\mathrm{I})$ which are neglected by HF. To further test the importance of correlation, we simulated the $\mathrm{Ag}_{2} \mathrm{O}$ cell with $100 \% \mathrm{HF}$ exchange and $100 \%$ PBE correlation, finding a lattice vector only $1.2 \%$ larger than experiment. Although the physical meaning of such a calculation is questionable, it does at least indicate that the overexpansions seen for $\mathrm{Ag}(\mathrm{I})$ species with $\mathrm{HF}$ are a result of the neglect of correlation.

The errors in the structural parameters, relative to experiment, for both GGA and HSE06 are also larger than typically seen, although not to the extreme seen for $\mathrm{Ag}(\mathrm{I})$ species with HF. HSE06 is seen to offer only limited improvement over GGA for the calculation of the unit-cell structure (in the case of $\mathrm{Ag}_{2} \mathrm{O}$ ) or to only give substantial improvement to some lattice vectors $\left(\mathrm{Ag}_{2} \mathrm{O}_{3}\right.$ and $\left.\mathrm{AgO}\right)$. Although the source of this is not apparent, many studies have discussed the possibility and role of Ag-Ag interactions. . $^{37,38,118-120}$ DFT (and hybrid-DFT) methods are known to fail to account for nonbonded van der Waals forces, ${ }^{121-123}$ as has been shown previously in the expansion of layered materials which are held together by dispersion forces, such as SnO (Refs. 124,125) and $\mathrm{V}_{2} \mathrm{O}_{5} \cdot{ }^{72,126}$ To begin to assess this, we have considered the effect of dispersion corrections through the application of the GGA-D2 methodology of Grimme, ${ }^{127-129}$ which adds dispersion corrections to the energy using a semiempirical pairwise force field. As the HSE06 approach is considerably more expensive than GGA, we initially trialled this only with the GGA approach.

The calculated lattice vectors for $\mathrm{Ag}_{2} \mathrm{O}_{3}$ and $\mathrm{Ag}_{2} \mathrm{O}$ using GGA and GGA-D2 are given in Table IV. For $\mathrm{Ag}_{2} \mathrm{O}_{3}$, the inclusion of dispersion corrections has a large effect. Not only does it reduce all three vectors, making them closer to the experimental values, but it also equalizes the difference to experiment in all three vectors. In the original GGA calculation, the $c$ vector was seen to have a greater error with respect to experiment than the $a$ and $b$ vectors. From the structure, the $c$ vector looks to be more strongly influenced by Ag-Ag interactions. As the GGA-D2 method removes this overexpansion, it is highly suggestive of the importance of these nonbonded interactions in the silveroxygen system. For $\mathrm{Ag}_{2} \mathrm{O}$, the GGA-D2 method also decreases the percentage difference in the lattice vectors relative to experiment. However, due to its cubic nature, meaning that any applied correction will inherently reduce the cell volume, no information on the appropriateness of this method can be gained.

For AgO (Table IV), the effect of dispersion corrections is not as conclusive. Although a marked improvement is seen in the $a$ and $b$ vectors, the $c$ vector actually lengthens, relative to the GGA $+U$ calculation (where $U=6 \mathrm{eV}$ ), taking it further from the experimental value. Furthermore, the potential error from using the same $U$ value for both $\operatorname{Ag}(\mathrm{I})$ and $\operatorname{Ag}(\mathrm{III})$ species, as mentioned previously, cannot be decoupled from the effect of the dispersion interactions. However, an overall improvement is seen in the cell, suggesting that dispersion forces are also important for this structure.

Although the predicted structures are closer to those reported experimentally, an average error to experiment of $1.5 \%$ is still seen, which is more in line with typical PBE errors. In addition, the improvement seen for $\mathrm{Ag}_{2} \mathrm{O} / \mathrm{Ag}_{2} \mathrm{O}_{3}$ differs from that for AgO. The varying success of the GGA-D2 approach most likely results from the parameter set it employs. The parameters used to determine the energy corrections are based on neutral species and the van der Waals radii for the atoms. The use of atomic-based parameters puts large dispersion coefficients on the Ag atoms and small forces on the oxygen atoms. This results in the interactions between $\mathrm{Ag}$ atoms being too strong and those between oxygen atoms being underestimated. Furthermore, the same parameters are employed for all silver atoms, regardless of their oxidation state, which will generate additional errors for the mixedvalence system than the single-valence materials, as the results show. This is due to the different polarizabilities of $\operatorname{Ag}(\mathrm{I})$ and 
TABLE IV. Calculated lattice vectors using GGA/GGA $+U$ and GGA-D2/GGA $+U$-D2 methods for $\mathrm{Ag}_{2} \mathrm{O}$ and $\mathrm{Ag}_{2} \mathrm{O}_{3} / \mathrm{AgO}$, where $U=$ $6 \mathrm{eV}$. Percentage changes to experiment (Refs. 5,7, and 9) are given in parentheses and all values are in $\AA$.

\begin{tabular}{|c|c|c|c|c|c|c|}
\hline \multirow[b]{2}{*}{ Property } & \multicolumn{2}{|c|}{$\mathrm{Ag}_{2} \mathrm{O}$} & \multicolumn{2}{|c|}{$\mathrm{Ag}_{2} \mathrm{O}_{3}$} & \multicolumn{2}{|c|}{$\mathrm{AgO}$} \\
\hline & GGA & GGA-D2 & GGA & GGA-D2 & $\mathrm{GGA}+U$ & $\mathrm{GGA}+U-\mathrm{D} 2$ \\
\hline$a$ & $4.844(2.4)$ & $4.804(1.5)$ & $13.096(1.8)$ & $13.067(1.5)$ & $4.804(-2.2)$ & $5.773(-1.5)$ \\
\hline$b$ & $4.844(2.4)$ & $4.804(1.5)$ & $10.697(2.0)$ & $10.652(1.5)$ & $4.510(5.2)$ & $3.523(1.1)$ \\
\hline$c$ & $4.844(2.4)$ & $4.804(1.5)$ & $3.834(4.6)$ & $3.720(1.5)$ & $5.562(1.1)$ & $5.616(2.1)$ \\
\hline
\end{tabular}

Ag(III) being modeled as identical. Despite these limitations, these preliminary results show that van der Waals corrections do offer a significant improvement for these materials. As the DFT-D2 methodology is unable to distinguish between the two oxidation states of $\mathrm{Ag}$, we have elected not to continue trialling this approach with HSE06 and HF.

Other studies have also criticized the parameter set used in the DFT-D2 approach, notably those of Conesa ${ }^{130}$ and Martinez-Casado et al. ${ }^{131}$ Conesa assessed the use of DFTD2 for modeling the energies of different polymorphs of $\mathrm{TiO}_{2}$ and $\mathrm{Al}_{2} \mathrm{O}_{3}$. One of the conclusions from his work is that dispersion coefficients for neutral species should not be used and parameters determined from ionic species are more appropriate, giving a better fit to experiment. Martinez-Casado et al. used a range of DFT and hybrid-DFT functionals to model the adsorption of a $\mathrm{He}$ atom on the $\mathrm{MgO}$ (100) surface. Their results showed that while the application of this approach qualitatively described the correct binding of $\mathrm{He}$, it failed to determine the correct binding energy, predicting an overbinding. The DFT-D2 has also been found to incorrectly model the structure of $\mathrm{SnO}$, with an approach using an ionic-based parameter set offering superior structural data. ${ }^{132}$ Alternative methods of modeling materials in which dispersion forces are important also exist and may offer improvement over the DFT-D2 method. ${ }^{122}$ These include, but are not limited to, the nonlocal van der Waals density functional (vdw-DF) ${ }^{133,134}$ and the improved DFT-D3 method. ${ }^{135}$

\section{CONCLUSIONS}

The results of this paper clearly show the deficiency of GGA for modeling the electronic structure of silver oxides. For $\mathrm{Ag}_{2} \mathrm{O}$, although GGA is able to correctly predict the general features of the band structures, in terms of their energy variation along the high-symmetry lines, it incorrectly shows it to be metallic. HSE06, however, gives a fundamental band gap of $1.2 \mathrm{eV}$, which is is good agreement with the experimental value of $1.3 \mathrm{eV} .{ }^{35} \mathrm{GGA}$ is also seen to underestimate the band gap for $\mathrm{Ag}_{2} \mathrm{O}_{3}$ by $1.4 \mathrm{eV}$, in comparison with the HSE06 results $(1.9 \mathrm{eV})$. For $\mathrm{AgO}$, the failure of GGA is even more dramatic, delocalizing the charge to give equivalent $\mathrm{Ag}$ (II) ions rather than the correct $\mathrm{Ag}(\mathrm{I}, \mathrm{III})$ mixed valence. This is improved using a GGA $+U$ methodology, where a $U$ value larger than $5.0 \mathrm{eV}$ is required to predict the true mixed-valence nature of this material. HSE06 not only gives improved structural data, but is also essential for obtaining a band gap in line with experiment. HF, however, fails to predict either the structure or band gaps correctly for all three oxides. Structural data arising from $\mathrm{Ag}(\mathrm{I})$ species is seen to be overestimated in comparison to experiment, whereas $\mathrm{Ag}(\mathrm{III})-\mathrm{O}$ bond lengths are slightly underestimated. Furthermore, band gaps predicted using $\mathrm{HF}$ are substantially too large, as expected for this approach.

The calculated band structures of $\mathrm{AgO}$ and $\mathrm{Ag}_{2} \mathrm{O}_{3}$ indicate that the fundamental band gaps are indirect in nature, 1.0 and $1.9 \mathrm{eV}$, respectively. The smallest direct band gaps, however, are only slightly larger in energy and are also the location of the optical band gaps (1.40 and $2.13 \mathrm{eV}$ ), respectively. $\mathrm{Ag}_{2} \mathrm{O}$ differs with these oxides in that it has a direct fundamental band gap of $1.1 \mathrm{eV}$ which is symmetry forbidden. Therefore, the optical band gap is larger, with a calculated value of $2.15 \mathrm{eV}$. This calls into question recent experimental optical band gaps from $\mathrm{Ag}_{2} \mathrm{O}$ nanoparticles and electrodeposited thin films of $1.46 \mathrm{eV}$. The close agreement of this with our calculated optical band gap of $\mathrm{AgO}$ suggests that the experimental value may not originate from pure $\mathrm{Ag}_{2} \mathrm{O}$, but possibly from $\mathrm{AgO}$ impurities or silver-deficient $\mathrm{Ag}_{2} \mathrm{O}$. This indicates the need for further study to clarify this discrepancy.

Finally, preliminary calculations have been conducted to consider the importance of nonbonded van der Waals interactions for the silver-oxygen system. The GGA-D2 method of Grimme highlights that the inclusion of dispersion corrections can significantly improve the structural prediction of these oxides, suggesting that these corrections are important. However, the atomic parameters derived for neutral species used in this method may not be appropriate for use with these oxides, which possess silver ions with different oxidation states. This is particularly true for $\mathrm{AgO}$, for which a distorted unit cell is still predicted with GGA $+U$-D2.

\section{ACKNOWLEDGMENTS}

This work was supported by Science Foundation Ireland through the Principal Investigators program (PI Grant Nos. 06/IN.1/I92 and 06/IN.1/I92/EC07). Calculations were performed on the IITAC and Lonsdale supercomputers as maintained by TCHPC, and the Stokes supercomputer as maintained by ICHEC. 
*allenje@tcd.ie

${ }^{\dagger}$ watsong@tcd.ie

${ }^{1}$ P. Niggli, Z. Kristallogr. 57, 253 (1922).

${ }^{2}$ M. O'Keeffe and J. O. Bovin, Am. Mineral. 63, 180 (1978).

${ }^{3}$ P. Jones, H. Rumpel, E. Schwarzmann, G. Sheldrick, and H. Paulus, Acta Crystallogr. Sect. B 35, 1435 (1979).

${ }^{4}$ J. J. Pireaux, M. Liehr, P. A. Thiry, J. P. Delrue, and R. Caudano, Surf. Sci. 141, 221 (1984).

${ }^{5}$ P. Norby, R. Dinnebier, and A. N. Fitch, Inorg. Chem. 41, 3628 (2002).

${ }^{6}$ B. Standke and M. Jansen, Angew. Chem. 97, 114 (1985).

${ }^{7}$ B. Standke and M. Jansen, Angew. Chem., Int. Ed. Engl. 24, 118 (1985).

${ }^{8}$ B. Standke and M. Jansen, Z. Anorg. Allg. Chem. 535, 39 (1986).

${ }^{9}$ M. Jansen and P. Fischer, J. Less-Common Met. 137, 123 (1988).

${ }^{10}$ B. Standke and M. Jansen, Angew. Chem. 98, 78 (1986).

${ }^{11}$ B. Standke and M. Jansen, Angew. Chem., Int. Ed. Engl. 25, 77 (1986).

${ }^{12}$ B. Standke and M. Jansen, J. Solid State Chem. 67, 278 (1987).

${ }^{13}$ G. I. N. Waterhouse, J. B. Metson, and G. A. Bowmaker, Polyhedron 26, 3310 (2007).

${ }^{14}$ A. N. Mansour, J. Phys. Chem. 94, 1006 (1990).

${ }^{15}$ W. Beesk, P. G. Jones, H. Rumpel, E. Schwarzmann, and G. M. Sheldrick, J. Chem. Soc. Chem. Commun. 14, 664 (1981).

${ }^{16}$ D. F. Smith and J. A. Gucinski, J. Power Sources 80, 66 (1999).

${ }^{17}$ D. F. Smith and C. Brown, J. Power Sources 96, 121 (2001).

${ }^{18}$ J. Pan, Y. Sun, Z. Wang, P. Wan, X. Liu, and M. Fan, J. Mater. Chem. 17, 4820 (2007).

${ }^{19}$ H. Q. Li, Y. G. Wang, P. He, and H. S. Zhou, Chem. Commun. 46, 2055 (2010).

${ }^{20}$ D. Dellasega, A. Facibeni, F. Di Fonzo, M. Bogana, A. Polissi, C. Conti, C. Ducati, C. S. Casari, A. Li Bassi, and C. E. Bottani, Nanotechnology 19, 475602 (2008).

${ }^{21}$ D. Dellasega, A. Facibeni, F. Di Fonzo, V. Russo, C. Conti, C. Ducati, C. S. Casari, A. Li Bassi, and C. E. Bottani, Appl. Surf. Sci. 255, 5248 (2009).

${ }^{22}$ X. Wang, H. F. Wu, Q. Kuang, R. B. Huang, Z. X. Xie, and L. S. Zheng, Langmuir 26, 2774 (2010).

${ }^{23}$ J. Tominaga, J. Phys. Condens. Matter 15, R1101 (2003).

${ }^{24}$ B. Fang, A. Gu, G. Wang, W. Wang, Y. Feng, C. Zhang, and X. Zhang, ACS Appl. Mater. Interfaces 1, 2829 (2009).

${ }^{25}$ W. Wang, Q. Zhao, J. Dong, and J. Li, Int. J. Hydrogen Energy 36, 7374 (2011).

${ }^{26}$ M. Fujimaki, K. Awazu, and J. Tominaga, J. Appl. Phys. 100, 074303 (2006).

${ }^{27}$ R. H. Crabtree, J. Organomet. Chem. 690, 5451 (2005).

${ }^{28}$ Q. Y. Tian, D. X. Shi, and Y. W. Sha, Molecules 13, 948 (2008).

${ }^{29}$ C. Tomasi, P. Mustarelli, and A. Magistris, J. Solid State Chem. 140, 91 (1998).

${ }^{30}$ M. Hosono, J. Kawamura, I. H., N. Kuwata, T. Kamiyama, and Y. Nakamura, J. Non-Cryst. Solids 244, 81 (1999).

${ }^{31}$ H. Takahashi, N. Rikitake, T. Sakuma, and Y. Ishii, Solid State Ionics 168, 93 (2004).

${ }^{32}$ Z. Wiśniewski, R. Wiśniewski, and J. L. Nowiński, Solid State Ionics 157, 275 (2003).

${ }^{33}$ A. Deb and A. K. Chatterjee, J. Phys. Condens. Matter 10, 11719 (1998).

${ }^{34}$ M. T. Czyżyk, R. A. de Groot, G. Dalba, P. Fornasini, A. Kisiel, F. Rocca, and E. Burattini, Phys. Rev. B 39, 9831 (1989).
${ }^{35}$ L. H. Tjeng, M. B. J. Meinders, J. van Elp, J. Ghijsen, and G. A. Sawatzky, Phys. Rev. B 41, 3190 (1990).

${ }^{36}$ G. B. Hoflund, Z. F. Hazos, and G. N. Salaita, Phys. Rev. B 62, 11126 (2000).

${ }^{37}$ A. Filippetti and V. Fiorentini, Phys. Rev. B 72, 035128 (2005).

${ }^{38}$ A. B. Gordienko, Y. N. Zhuravlev, and D. G. Fedorov, Phys. Solid State 49, 223 (2007).

${ }^{39}$ F. Pei, S. Wu, G. Wang, M. Xu, S.-Y. Wang, and L.-Y. Chen, J. Korean Phys. Soc. 55, 1243 (2009).

${ }^{40}$ A. J. Varkey and A. F. Fort, Sol. Energy Mater. Sol. Cells 29, 253 (1993).

${ }^{41}$ L.-M. Lyu, W.-C. Wang, and M. H. Huang, Chem. Eur. J. 16, 14167 (2010).

${ }^{42}$ Y. Ida, S. Watase, T. Shinagawa, M. Watanabe, M. Chigane, M. Inaba, A. Tasaka, and M. Izaki, Chem. Mater. 20, 1254 (2008).

${ }^{43}$ P. Behrens, S. Aßmann, U. Bilow, C. Linke, and M. Jansen, Z. Anorg. Allg. Chem. 625, 111 (1999).

${ }^{44}$ L. van Wüllen, S. Vensky, W. Hoffbauer, and M. Jansen, Solid State Sci. 7, 920 (2005).

${ }^{45}$ J. K. Burdett and S. Sevov, J. Am. Chem. Soc. 117, 12788 (1995).

${ }^{46}$ D. Lützenkirchen-Hecht and H.-H. Strehblow, Surf. Interface Anal. 41, 820 (2009).

${ }^{47}$ M. Bielmann, P. Schwaller, P. Ruffieux, O. Gröning, L. Schlapbach, and P. Gröning, Phys. Rev. B 65, 235431 (2002).

${ }^{48}$ K.-T. Park, D. L. Novikov, V. A. Gubanov, and A. J. Freeman, Phys. Rev. B 49, 4425 (1994).

${ }^{49}$ J. P. Allen, D. O. Scanlon, and G. W. Watson, Phys. Rev. B 81, 161103 (2010).

${ }^{50}$ G. Kresse and J. Hafner, Phys. Rev. B 49, 14251 (1994).

${ }^{51}$ G. Kresse and J. Furthmüller, Phys. Rev. B 54, 11169 (1996).

${ }^{52}$ P. E. Blöchl, Phys. Rev. B 50, 17953 (1994).

${ }^{53}$ G. Kresse and D. Joubert, Phys. Rev. B 59, 1758 (1999).

${ }^{54}$ J. P. Perdew, K. Burke, and M. Ernzerhof, Phys. Rev. Lett. 77, 3865 (1996).

${ }^{55}$ S. Heyd, G. E. Scuseria, and M. Ernzerhof, J. Chem. Phys. 118, 8207 (2003).

${ }^{56}$ A. V. Krukau, O. A. Vydrov, A. F. Izmaylov, and G. E. Scuseria, J. Chem. Phys. 125, 224106 (2006).

${ }^{57}$ D. O. Scanlon, A. Walsh, and G. W. Watson, Chem Mater. 21, 4568 (2009).

${ }^{58}$ J. Heyd and G. E. Scuseria, J. Chem. Phys. 121, 1187 (2004).

${ }^{59}$ J. Heyd, J. E. Peralta, G. E. Scuseria, and R. L. Martin, J. Chem. Phys. 123, 174101 (2005).

${ }^{60}$ M. Marsman, J. Paier, A. Stroppa, and G. Kresse, J. Phys. Condens. Matter 20, 064201 (2008).

${ }^{61}$ S. Chen, Z. G. Gong, A. Walsh, and S. H. Wei, Appl. Phys. Lett. 94, 041903 (2009).

${ }^{62}$ J. Paier, R. Asahi, A. Nagoya, and G. Kresse, Phys. Rev. B 79, 115126 (2009).

${ }^{63}$ D. O. Scanlon and G. W. Watson, Chem. Mater. 21, 5435 (2009).

${ }^{64}$ D. O. Scanlon and G. W. Watson, Appl. Phys. Lett. 97, 131904 (2010).

${ }^{65}$ A. Stroppa and G. Kresse, Phys. Rev. B. 79, 201201(R) (2009).

${ }^{66}$ D. O. Scanlon and G. W. Watson, J. Phys. Chem. Lett. 1, 3195 (2010).

${ }^{67}$ D. O. Scanlon and G. W. Watson, J. Phys. Chem. Lett. 1, 2582 (2010).

${ }^{68}$ I. D. Prodan, G. E. Scuseria, and R. L. Martin, Phys. Rev. B 73, 045104 (2006). 
${ }^{69}$ J. L. F. Da Silva, M. V. Ganduglia-Pirovano, J. Sauer, V. Bayer, and G. Kresse, Phys. Rev. B 75, 045121 (2007).

${ }^{70}$ A. Stroppa and S. Picozzi, Phys. Chem. Chem. Phys. 12, 5405 (2010).

${ }^{71}$ E. N. Brothers, A. F. Izmaylov, J. O. Normand, V. Barone, and G. E. Scuseria, J. Chem. Phys. 129, 011102 (2008).

${ }^{72}$ D. O. Scanlon, A. Walsh, B. J. Morgan, and G. W. Watson, J. Phys. Chem. C 112, 9903 (2008).

${ }^{73}$ D. O. Scanlon, N. M. Galea, B. J. Morgan, and G. W. Watson, J. Phys. Chem. C 113, 11095 (2009).

${ }^{74}$ R. Coquet and D. J. Willock, Phys. Chem. Chem. Phys. 7, 3819 (2005).

${ }^{75}$ P. R. L. Keating, D. O. Scanlon, and G. W. Watson, J. Phys. Condens. Matter 21, 405502 (2009).

${ }^{76}$ B. J. Morgan, D. O. Scanlon, and G. W. Watson, J. Mater. Chem. 19, 5175 (2009).

${ }^{77}$ D. O. Scanlon, A. Walsh, B. J. Morgan, M. Nolan, J. Fearon, and G. W. Watson, J. Phys. Chem. C 111, 7971 (2007).

${ }^{78}$ M. Nolan and G. W. Watson, J. Chem. Phys. 125, 144701 (2006).

${ }^{79}$ S. L. Dudarev, G. A. Botton, S. Y. Savrasov, C. J. Humphreys, and A. P. Sutton, Phys. Rev. B 57, 1505 (1998).

${ }^{80}$ F. D. Murnaghan, Proc. Natl. Acad. Sci. USA 30, 244 (1944).

${ }^{81}$ M. Gajdos, K. Hummer, G. Kresse, J. Furthmüller, and F. Bechstedt, Phys. Rev. B 73, 045112 (2006).

${ }^{82}$ B. Adolph, J. Furthmüller, and F. Beckstedt, Phys. Rev. B 63, 125108 (2001).

${ }^{83}$ L. E. Ramos, J. Paier, G. Kresse, and F. Bechstedt, Phys. Rev. B 78, 195423 (2008)

${ }^{84}$ J. Paier, M. Marsman, and G. Kresse, Phys. Rev. B 78, 121201 (2008).

${ }^{85}$ X. Nie, S. H. Wei, and S. B. Zhang, Phys. Rev. Lett. 88, 066405 (2002).

${ }^{86}$ A. Walsh, J. L. F. Da Silva, Y. Yan, M. M. Al-Jassim, and S. H. Wei, Phys. Rev. B 79, 073105 (2009).

${ }^{87}$ A. Walsh, Y. Yan, M. N. Huda, M. M. Al-Jassim, and S. H. Wei, Chem. Mater. 21, 547 (2009).

${ }^{88}$ A. Kirfel and K. Eichhorn, Acta Crystallogr. Sect. A 46, 271 (1990).

${ }^{89}$ C. E. Housecroft and A. G. Sharpe, Inorganic Chemistry (Pearson Education, Harlow, UK, 2001).

${ }^{90}$ D. O. Scanlon and G. W. Watson, J. Mater. Chem. 21, 3655 (2011).

${ }^{91}$ J. P. Allen, M. K. Nilsson, D. O. Scanlon, and G. W. Watson, Phys. Rev. B 83, 035207 (2011).

${ }^{92}$ C. J. Bradley and A. P. Cracknell, Mathematical Theory of Symmetry in Solids (Oxford University Press, Oxford, UK, 1972).

${ }^{93}$ D. O. Scanlon, B. J. Morgan, G. W. Watson, and A. Walsh, Phys. Rev. Lett. 103, 096405 (2009).

${ }^{94}$ D. O. Scanlon and G. W. Watson, Phys. Chem. Chem. Phys. 13, 9667 (2011).

${ }^{95}$ N. Umezawa, O. Shuxin, and J. Ye, Phys. Rev. B 83, 035202 (2011).

${ }^{96}$ R. Restori and D. Schwarzenbach, Acta Crystallogr. Sect. B 42, 201 (1986).

${ }^{97}$ H. Shi, R. Asahi, and C. Stampfl, Phys. Rev. B 75, 205125 (2007).

${ }^{98}$ K. Yvon, A. Bezinge, P. Tissot, and P. Fischer, J. Solid State Chem. 65, 225 (1986).
${ }^{99}$ A. Stergiou, I. Kerasiotis, and C. Stergiou, J. Optoelectron. Adv. Mater. 9, 1772 (2007).

${ }^{100}$ D. O. Scanlon, B. J. Morgan, and G. W. Watson, J. Chem. Phys. 131, 124703 (2009).

${ }^{101}$ D. O. Scanlon, A. Walsh, B. J. Morgan, G. W. Watson, D. J. Payne, and R. G. Egdell, Phys. Rev. B 79, 035101 (2009).

${ }^{102}$ L. Wang, T. Maxisch, and G. Ceder, Phys. Rev. B 73, 195107 (2006).

${ }^{103}$ B. E. Breyfogle, C. J. Hung, M. G. Shumsky, and J. A. Switzer, J. Electrochem. Soc. 143, 2714 (1996).

${ }^{104}$ N. Ravi Chandra Raju, K. Jagadeesh Kumar, and A. Subrahmanyam, J. Phys. D 42, 135411 (2009).

${ }^{105}$ M. Beaudoin, M. Meunier, and C. J. Arenault, Phys. Rev. B 47, 2197 (1993).

${ }^{106}$ G. P. Joshi, N. S. Saxena, R. Mangal, A. Mishra, and T. P. Sharma, Bull. Mater. Sci. 26, 387 (2003).

${ }^{107}$ N. J. Tharayil, R. Raveendran, A. V. Vaidyan, and P. G. Chithra, Indian J. Eng. Mater. Sci. 15, 489 (2008).

${ }^{108}$ J. P. Dahl and A. C. Switendick, J. Phys. Chem. Solids 27, 931 (1966).

${ }^{109}$ H.-X. Deng, S.-S. Li, and J. Li, J. Phys. Chem. C 114, 4841 (2010).

${ }^{110}$ W. Siripala and J. R. P. Jaykody, Sol. Energy Mater. 14, 23 (1986).

${ }^{111}$ C. Jayewardena, K. P. Hewaparakrama, D. L. A. Wijewardena, and H. Guruge, Sol. Energy Mater. Sol. Cells 56, 29 (1998).

${ }^{112}$ C. A. N. Fernando and S. K. Wetthasinghe, Sol. Energy Mater. Sol. Cells 63, 299 (2000).

${ }^{113}$ R. Garuthara and W. Siripala, J. Lumin. 121, 173 (2006).

${ }^{114}$ L. C. Wang and M. Tao, Electrochem. Solid-State Lett. 10, H248 (2007).

${ }^{115}$ J. N. Nian, C. C. Tsai, P. C. Lin, and H. S. Teng, J. Electrochem. Soc. 156, H567 (2009).

${ }^{116}$ W. Wei, X. Mao, L. A. Ortiz, and D. R. Sadoway, J. Mater. Chem. 21, 432 (2011).

${ }^{117}$ E. Aprà, E. Stefanovich, R. Dovesi, and C. Roetti, Chem. Phys. Lett. 186, 329 (1991).

${ }^{118}$ P. Pyykkö, Chem. Rev. 97, 597 (1997).

${ }^{119}$ E. Ruiz, S. Alvarez, A. Alemany, and R. Evarestov, Phys. Rev. B 56, 7189 (1997).

${ }^{120}$ S. Sculfort, P. Croizat, A. Messaoudi, M. Bénard, M.-M. Rohmer, R. Welter, and P. Braunstein, Angew. Chem. Int. Ed. 48, 9663 (2009).

${ }^{121}$ W. Koch, E. Jan Baerends, and M. C. Holthausen, A Chemist's Guide to Density Functional Theory (Wiley-VCH, Weinheim, 2001).

${ }^{122}$ J. F. Dobson, K. McLennan, A. Rubio, J. Wang, T. Gould, H. M. Le, and B. P. Dinte, Aust. J. Chem. 54, 513 (2001).

${ }^{123} \mathrm{Q}$. Wu and W. Yang, J. Chem. Phys. 116, 515 (2002).

${ }^{124}$ G. W. Watson, J. Chem. Phys. 114, 758 (2001).

${ }^{125}$ A. Walsh and G. W. Watson, Phys. Rev. B 70, 235114 (2004).

${ }^{126}$ E. Londero and E. Schröder, Phys. Rev. B 82, 054116 (2010).

${ }^{127}$ S. Grimme, J. Comput. Chem. 25, 1463 (2004).

${ }^{128}$ S. Grimme, J. Comput. Chem. 27, 1787 (2006).

${ }^{129}$ T. Bučko, J. Hafner, S. Lebègue, and J. G. Ángyán, J. Phys. Chem. A 114, 11814 (2010). 
${ }^{130}$ J. C. Conesa, J. Phys. Chem. C 114, 22718 (2010).

${ }^{131}$ R. Martinez-Casado, G. Mallia, D. Usvyat, L. Maschio, S. Casassa, M. Schütz, and N. M. Harrison, J. Chem. Phys. 134, 014706 (2011).

${ }^{132}$ J. P. Allen, D. O. Scanlon, S. C. Parker, and G. W. Watson, J. Phys. Chem. C (2011), doi: 10.1021/jp205148y.
${ }^{133}$ M. Dion, H. Ryberg, E. Schröder, D. C. Langreth, and B. I. Lundqvist, Phys. Rev. Lett. 92, 246401 (2004).

${ }^{134}$ J. Klimeš, D. R. Bowler, and A. Michaelides, J. Phys. Condens. Matter 22, 022201 (2010).

${ }^{135}$ S. Grimme, J. Antony, S. Ehrlich, and H. Krieg, J. Chem. Phys. 132, 154104 (2010). 